\title{
Article \\ Predictors of Word and Text Reading Fluency of Deaf Children in Bilingual Deaf Education Programmes
}

\author{
Ellen Ormel ${ }^{1}$, Marcel R. Giezen ${ }^{2}\left(\mathbb{D}\right.$, Harry Knoors ${ }^{3,4}$, Ludo Verhoeven ${ }^{3}$ and Eva Gutierrez-Sigut ${ }^{5, *}$ \\ 1 Centre for Language Studies, Radboud University, 6525 XZ Nijmegen, The Netherlands; ellen.ormel@ru.nl \\ 2 Basque Centre on Cognition Brain and Language, 20009 Donostia, Spain; giezenmr@gmail.com \\ 3 Behavioural Science Institute, Radboud University, 6525 XZ Nijmegen, The Netherlands; \\ harry.knoors@ru.nl (H.K.); ludo.verhoeven@ru.nl (L.V.) \\ 4 Kentalis, Van Vollenhovenlaan 659-661, 3527 JP Utrecht, The Netherlands \\ 5 Department of Psychology, University of Essex, Colchester CO4 3SQ, UK \\ * Correspondence: eva.gutierrez@essex.ac.uk
}

check for

updates

Citation: Ormel, Ellen, Marcel R.

Giezen, Harry Knoors, Ludo Verhoeven, and Eva Gutierrez-Sigut. 2022. Predictors of Word and Text Reading Fluency of Deaf Children in Bilingual Deaf Education Programmes. Languages 7: 51. https://doi.org/10.3390/ languages7010051

Academic Editor: Ana I. Schwartz

Received: 17 November 2021

Accepted: 9 February 2022

Published: 25 February 2022

Publisher's Note: MDPI stays neutral with regard to jurisdictional claims in published maps and institutional affiliations.

Copyright: (c) 2022 by the authors. Licensee MDPI, Basel, Switzerland. This article is an open access article distributed under the terms and conditions of the Creative Commons Attribution (CC BY) license (https:/ / creativecommons.org/licenses/by/ $4.0 /)$.

\begin{abstract}
Reading continues to be a challenging task for most deaf children. Bimodal bilingual education creates a supportive environment that stimulates deaf children's learning through the use of sign language. However, it is still unclear how exposure to sign language might contribute to improving reading ability. Here, we investigate the relative contribution of several cognitive and linguistic variables to the development of word and text reading fluency in deaf children in bimodal bilingual education programmes. The participants of this study were 62 school-aged (8 to 10 years old at the start of the 3-year study) deaf children who took part in bilingual education (using Dutch and Sign Language of The Netherlands) and 40 age-matched hearing children. We assessed vocabulary knowledge in speech and sign, phonological awareness in speech and sign, receptive fingerspelling ability, and short-term memory at time 1 (T1). At times 2 (T2) and 3 (T3), we assessed word and text reading fluency. We found that (1) speech-based vocabulary strongly predicted word and text reading at T2 and T3, (2) fingerspelling ability was a strong predictor of word and text reading fluency at $\mathrm{T} 2$ and T3, (3) speech-based phonological awareness predicted word reading accuracy at T2 and T3 but did not predict text reading fluency, and (4) fingerspelling and STM predicted word reading latency at T2 while sign-based phonological awareness predicted this outcome measure at T3. These results suggest that fingerspelling may have an important function in facilitating the construction of orthographical/phonological representations of printed words for deaf children and strengthening word decoding and recognition abilities.
\end{abstract}

Keywords: deafness; reading development; bimodal bilingual education; word reading; text reading; sign language; phonological awareness; vocabulary; fingerspelling

\section{Introduction}

Reading is a challenging task for most deaf children. It has been consistently observed that, at the group level, deaf children show lower reading levels than hearing children of the same age (e.g., Karchmer and Mitchell 2003; Marschark et al. 2007; Musselman 2000; Qi and Mitchell 2012; Wauters et al. 2006; Moreno-Pérez et al. 2015). Many deaf children experience difficulties with written word recognition and reading comprehension (e.g., Kelly 2003; Merrills et al. 1994; Wauters et al. 2006) that have been found to persist in adulthood (see, e.g., Bélanger and Rayner 2015; Wauters et al. 2021). Research with hearing children has established that vocabulary knowledge, phonological awareness (i.e., ability to recognize and manipulate the sub-lexical structure of words), fluent word recognition, and phonological short-term memory are strong predictors of reading skills in hearing children (e.g., Castles and Coltheart 2004; Dickinson et al. 2003; Verhoeven et al. 2011). However, relatively few studies have examined multiple predictors of reading development in deaf children (e.g., Easterbrooks and Huston 2008; Kyle and Harris 2010, 2011; Spencer and 
Oleson 2008), and an even smaller number of studies have examined predictors of reading development in deaf children enrolled in bilingual education in both sign language (SL) and the surrounding spoken/written language (e.g., Scott and Hoffmeister 2016; Crume et al. 2021; Yiu et al. 2019).

Bilingual education has the potential to provide students, particularly those with little access to speech, with alternative routes to increase their reading skills. However, it is still unclear whether-and how-SL instruction effectively supports reading development. Some researchers have proposed that the development of sign-based phonological awareness can be generalized to written language (McQuarrie and Abbott 2013; McQuarrie and Parrila 2009, 2014). Other researchers have highlighted the beneficial role of fingerspelling, as a way to link SL vocabulary to printed words through chaining (Humphries and MacDougall 1999; Padden and Ramsey 2000), as a way to develop orthographic learning (Miller et al. 2021), or as an alternative way to manipulate the sub-lexical structure of words (see, e.g., Antia et al. 2020; Lederberg et al. 2019). Here, we investigated the contribution of different cognitive and linguistic variables to the development of word and text reading skills in a longitudinal study with 8-10-year-old deaf children participating in bilingual programmes. The children attended schools for the deaf where both spoken/written Dutch and Sign Language of the Netherlands (NGT) were part of the curriculum. In addition to speech-based vocabulary and phonological awareness, and short-term memory, we investigated whether sign-based vocabulary and phonological awareness, and fingerspelling ability, predict word and text reading fluency. In the rest of the introduction, we discuss relevant previous literature on each of these predictors.

\section{Vocabulary}

Knowledge of word meanings is one of the strongest predictors of word decoding and reading comprehension in hearing readers, including early readers, second-grade children, and adults (see, e.g., Verhoeven et al. 2011; Cates et al. 2021). Vocabulary knowledge is also one of the most important predictors of reading success in deaf readers (Aarnoutse and van Leeuwe 1998; Dillon et al. 2012; Geers and Moog 1989; Kyle and Harris 2006, 2010, 2011; Moores and Sweet 1990; Cates et al. 2021; Wauters et al. 2021), with some researchers suggesting that vocabulary might be a stronger predictor of reading for deaf than for hearing readers (for a recent discussion, see Wauters et al. 2021). Kyle et al. (2016) found that expressive vocabulary and speechreading ability were strong predictors of reading in deaf children aged 5 to 14 years. Furthermore, Moreno-Pérez et al. (2015) found that vocabulary was the strongest predictor of reading ability in deaf readers, followed by reading speed, speech phonological awareness, and speechreading ability. Similar results have been found for deaf children with cochlear implants (CIs; see, e.g., Connor and Zwolan 2004; Dillon et al. 2012; Kyle et al. 2016). For example, Connor and Zwolan (2004) found that vocabulary was a strong predictor of reading comprehension for children with CIs after controlling for age of implantation, amount of time using the implant, and socioeconomic status.

Many prior studies identifying vocabulary as a strong predictor of reading achievement in deaf children have focused on expressive vocabulary (e.g., Easterbrooks and Huston 2008; Kyle and Harris 2006; Kyle et al. 2016; Herman et al. 2019). Measuring expressive vocabulary allows researchers to deal with the variability in language background typically found in deaf children. Specifically, allowing the children to give an oral or signed response (or a mixture of both) to the test items allows for a fair measurement of children's global vocabulary knowledge. This global measure is independent of which is the child's preferred language, or how proficient they are in either the spoken or the sign language. However, measuring expressive vocabulary as a whole does not allow exploring the extent to which speech- and signed-based vocabularies contribute to reading skill. Due to the lack of sign-based vocabulary tests for many sign languages, most previous studies investigating receptive vocabulary only measured speech-based vocabulary (e.g., MorenoPérez et al. 2015). In contrast, in the current study, we examined receptive speech- and 
SL-based vocabularies separately, which allowed us to explore the relationship between vocabulary knowledge in both modalities and their relative contribution to reading (for a similar approach, see Hermans et al. 2008a, 2008b; Hermans et al. 2010).

\section{Phonological Awareness}

The link between phonological awareness and reading in hearing children is well established: a higher ability to recognize and manipulate the sub-lexical structure of language is related to a higher reading ability (for a recent review, see Castles et al. 2018). Whether speech-based phonological awareness is a strong predictor of reading success in deaf readers is still a matter of intense debate. Some studies have found evidence for similar links between phonological awareness and reading ability in deaf readers as observed in hearing children (e.g., Dyer et al. 2003; Easterbrooks and Huston 2008; Harris and Beech 1998; Luetke-Stahlman and Nielsen 2003; Buchanan-Worster et al. 2020; Herman et al. 2019). For example, Buchanan-Worster et al. (2020) recently found moderate to strong correlations between phonological awareness and single-word reading in both deaf and hearing children. Herman et al. (2019) also found that several tasks measuring phonological awareness (i.e., phoneme deletion, spoonerism, and sequencing) were predictive of singleword reading in oral deaf children. However, other researchers have argued that having speech-based phonological awareness is of less or no importance in reading acquisition for deaf compared to hearing children (Hanson and Fowler 1987; Izzo 2002; Kyle and Harris 2006; Miller 1997; Mayberry et al. 2011). Similarly, many deaf children and adults do not seem to rely on phonological coding during visual word recognition (e.g., Bélanger et al. 2012; Ormel et al. 2010; Costello et al. 2021; but see, e.g., Bouton et al. 2015; MacSweeney et al. 2013; Transler and Reitsma 2005 for phonological effects). Consistent with this finding, recent research suggests that phonological coding may not be the driving force in determining reading ability in many deaf readers (for discussion, see Emmorey 2020; Emmorey and Lee 2021; Gutierrez-Sigut et al. 2017, 2019, 2022; Miller 2010). For example, a recent study with adult readers of Spanish showed that deaf readers activated phonological information from words during written word recognition. However, unlike for hearing readers, the use of phonology was not correlated with reading ability for deaf readers (Gutierrez-Sigut et al. 2017), suggesting that phonological processing might play a reduced role in deaf readers' reading comprehension.

Importantly, these studies only looked at speech-based phonological knowledge. Although deaf children generally have limited access to spoken language phonology, deaf children who sign (including those participating in bilingual programmes) also acquire phonological knowledge in a manual-visual language and develop sign-based phonological awareness. Sign-based phonological knowledge has been found to correlate with speechbased phonological awareness (Corina et al. 2014) and, importantly, with reading abilities in deaf students (McQuarrie and Abbott 2013). Specifically, McQuarrie and Abbott (2013) found low sensitivity to speech-based phonology in deaf children (see also McQuarrie and Parrila 2009) but moderate significant correlations between phonological awareness of American Sign Language and both word recognition and reading comprehension (cf. Holmer et al. 2017; Keck and Wolgemuth 2020). This pattern of results suggests that for deaf children whose first language is an SL, sign-based phonological awareness can be the foundation that supports reading (for further discussion, see (McQuarrie and Parrila 2014; Petitto et al. 2016)). In the current study, both speech-based and sign-based phonological awareness were therefore included as predictor variables.

\section{Fingerspelling}

Deaf signers have access to the manual representation of printed letters through fingerspelling. Teachers of deaf children have traditionally exploited this resource by explicitly linking written words, fingerspelling, and signs when teaching deaf children new printed vocabulary ('chaining'; Padden and Ramsey 2000). Some researchers noticed the utility of this practice early on (Humphries and MacDougall 1999; Padden and Ramsey 2000) 
and proposed that fingerspelling proficiency may contribute to deaf children's early reading development (Harris and Beech 1998; Treiman and Hirsh-Pasek 1983; Allen 2015). In a recent study with adult fluent signers, Stone et al. (2015) found that fingerspelling predicted word reading, above SL fluency. However, the mechanisms through which fingerspelling might support reading in deaf readers are not yet understood. A handful of recent studies offer divergent explanations for this seemingly beneficial role of fingerspelling. On the one hand, Miller et al. (2021) suggest that fingerspelling facilitates orthographic learning independently of speech phonology. The authors conducted an intervention study with four pre-school deaf children and observed that fingerspelling mediated the development of orthographic knowledge, independently of the children's phonological skills. On the other hand, it has been proposed that fingerspelling can carry some phonological information from printed words (for details, see Haptonstall-Nykaza and Schick 2007; Sehyr et al. 2016) and hence support the development of phonological representations of speech. Sehyr et al. (2016) found a phonological effect when adult signers recalled lists of fingerspelled words, indicating that fingerspelled words are coded using a speech-based phonological code. In the same line, Antia et al. (2020) and Lederberg et al. (2019) propose that fingerspelling offers an alternative way to manipulate the sub-lexical structure of words. Lederberg et al. (2019) studied the abilities underlying reading skill in oral deaf children and signers from pre-school to second grade. They found that the ability to manipulate the sub-lexical structure of words was strongly related to reading development for all deaf children. For the signers, fingerspelling supported visual access to phonology. In the current study, we further investigate the role of fingerspelling ability as a predictor of word and text reading fluency.

\section{Short-Term Memory (STM)}

Finally, several studies have found smaller short-term memory (STM) spans for deaf children compared to their hearing peers (e.g., Conrad 1970; Krakow and Hanson 1985; Marschark and Mayer 1998; Pisoni et al. 1999, 2011), which has been linked to differences in phonological access and processing. Specifically, hearing children may experience a facilitative effect of speech coding in phonological short-term memory performance (Perfetti and Sandak 2000; Marschark et al. 2002). It should be noted, however, that significant correlations between short-term memory capacity, phonological coding, and reading performance are not always observed for deaf readers (e.g., Waters and Doehring 1990; Bélanger and Rayner 2015; Kyle and Harris 2006, 2010, 2011; but see also Daneman et al. 1995; Harris and Moreno 2004). In a recent study, Sehyr et al. (2016) found a similar speech-based phonological similarity effect (i.e., recall of printed words was lower in lists with phonologically similar than phonologically dissimilar items) for printed words in adult deaf signers and hearing participants matched in reading skill. Moreover, the authors found positive correlations between accuracy recalling printed words and both reading skill and phonological awareness. Hirshorn et al. (2015) found correlations between serial recall performance and reading comprehension in oral adult deaf readers but not deaf signers, suggesting that phonological access may mediate the positive relation between auditory short-term memory and reading abilities in some studies. Consistent with this idea, recent studies have reported positive correlations between auditory short-term memory and reading comprehension in children and adolescents with CIs (e.g., Bharadwaj et al. 2015; Edwards et al. 2016; but see also Herman et al. 2019 for contrasting findings).

Given the mixed results for the contribution of short-term memory to reading development in deaf children, short-term memory was also included as a predictor in the current study.

\section{Present Study}

In the current study, we investigated the predictive value of several cognitive and linguistic variables (receptive vocabulary and phonological awareness in both modalities, fingerspelling recognition and short-term memory) for word and text reading fluency in 
a 2-year longitudinal study of deaf children in year 3 and year 5 of bilingual education programmes. Variables of interest included speech and sign phonological awareness, finger spelling, and short-term memory, in addition to vocabulary.

The predictor variables were measured when the deaf children were either in year 3 or year 5 . Word and text reading fluency were assessed one year later (time 2) and two years later (time 3). At time 2 and time 3, word and text reading fluency were also assessed in a group of hearing children of the same age as the deaf children (the children were either in year 3 or year 5 at time 2), to examine performance gaps in word and/or text reading fluency between deaf children and their hearing peers.

\section{Methods}

\subsection{Participants}

Participants in the current study consisted of 62 severely or profoundly deaf children in year 3 ( $\sim 8$ years old) and year 5 ( $\sim 10$ years old) of a bilingual education programme in the Netherlands (hearing loss > $80 \mathrm{~dB}, 27$ girls-35 boys; although 18 had a cochlear implant fitted at the time of the first testing session; 6 girls-12 boys). Sign Language of the Netherlands (Nederlandse Gebarentaal/NGT) or Sign supported Dutch (SSD) were used as the main language of instruction. Moreover, children received specific NGT instruction for approximately four hours a week from the age of four. Most deaf participants also attended a sign-oriented preschool from the age of 2-3 years.

At the start of the study, 30 children were 8 years old (mean age: 95 months, SD: 0.49 months) and 32 children 10 years old (mean age: 119 months, SD: 0.47 months). All children attended the school year expected for their chronological age (either year 3 or year 5). In total, 40 age-matched $(t(81.6)=-5.01, p>0.05)$ hearing children (23 boys; 17 girls; youngest group, mean age: 111 months, SD: 9.3 months; oldest group, mean age: 132 months, SD: 6.1 months, at year 2 of the study) with typical development were also tested on the word reading fluency and text reading fluency tasks in order to contextualize the performance of the deaf participants in comparison to a group of hearing peers of the same age and school year (details of the comparison between deaf and hearing children can be found in Appendix B). The participating school boards and Kentalis/Auris research boards approved the study.

\subsection{Design and Procedure}

The deaf children were tested once a year on three different occasions: Time 1 (T1), time 2 (T2), and time 3 (T3; see Figure 1). Word and text reading fluency were assessed (T2 and T3) for both deaf and hearing children. The children were individually tested in a quiet room at the child's school in 3 different sessions of approximately 15-20 min, 1 session a day across 3 consecutive days.

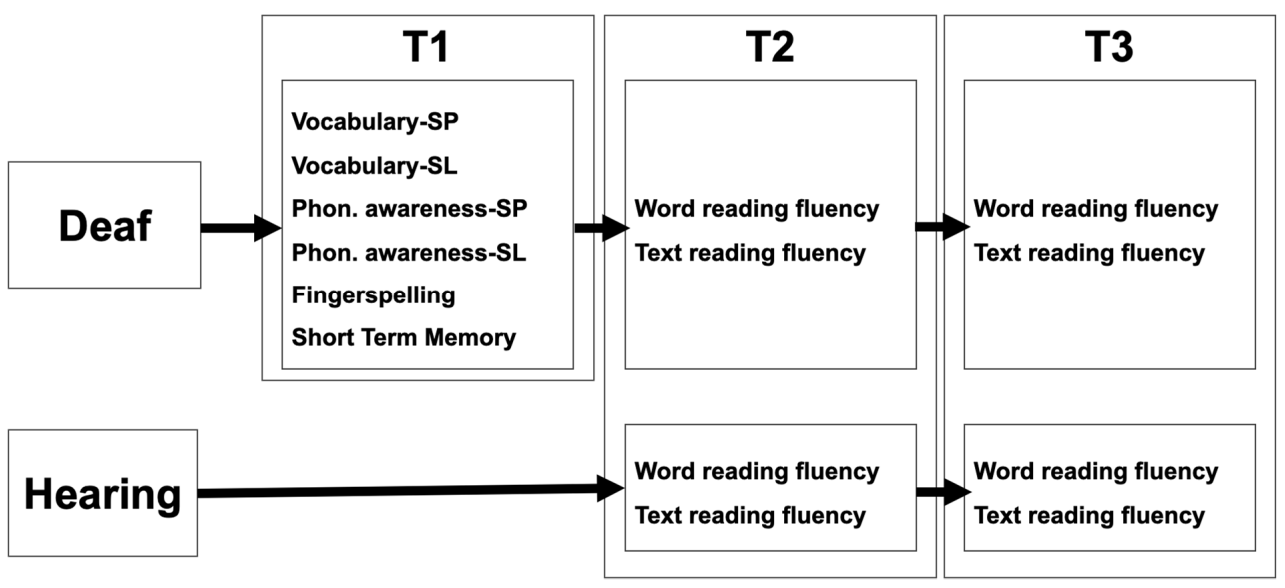

Figure 1. Detailed testing schedule across the years for deaf and hearing participants. 


\subsection{Materials}

\subsubsection{Predictors}

Table 1 describes the various tests used in the present study. Both speech and sign vocabulary, short term memory, and the signed-based phonological awareness tests were part of standardized tests (for references, see Table 1). The speech phonological awareness and fingerspelling recognition tasks were developed specifically for this study and are described in more detail in the text below. The stimuli used in these tasks can be found in Appendix A. Table 2 shows an overview of the correlations between the predictor variables for deaf children at $\mathrm{T} 1$.

Table 1. Details of the study measures.

\begin{tabular}{|c|c|c|c|c|c|}
\hline Predictor & Source & $\begin{array}{l}\text { Dependent } \\
\text { Variable }\end{array}$ & Method & Response Type & Task Description \\
\hline $\begin{array}{c}\text { Vocabulary-speech } \\
\text { (VocSP) }\end{array}$ & $\begin{array}{l}\text { Receptive vocabulary } \\
\text { test from: Taaltest } \\
\text { Alle Kinderen (TAK: } \\
\text { Language Test for All } \\
\text { Children; Verhoeven } \\
\text { and Vermeer 2001) }\end{array}$ & $\begin{array}{l}\text { Number of correct } \\
\text { responses }\end{array}$ & $\begin{array}{l}\text { In-person with test } \\
\text { administrator }\end{array}$ & $\begin{array}{l}\text { Multiple choice: } \\
\text { printed words }\end{array}$ & $\begin{array}{l}\text { The test administrator says } \\
\text { aloud each of the } 96 \text { target } \\
\text { words while the child, } \\
\text { sitting opposite, looks at } \\
\text { them. It is crucial that the } \\
\text { mouth of the administrator } \\
\text { is clearly visible. The child } \\
\text { is asked to select one of } \\
\text { four alternatives after being } \\
\text { exposed to each item. } \\
\text { Children responses are } \\
\text { based on speechreading in } \\
\text { addition to any residual } \\
\text { hearing. The task is } \\
\text { designed to simulate } \\
\text { day-to-day } \\
\text { speech-recognition. }\end{array}$ \\
\hline $\begin{array}{l}\text { Vocabulary-sign } \\
\text { (VocSL) }\end{array}$ & $\begin{array}{l}\text { Test-Nederlandse } \\
\text { Gebarentaal (TNGT; } \\
\text { Hermans et al. 2007) }\end{array}$ & $\begin{array}{l}\text { Number of correct } \\
\text { responses }\end{array}$ & Computerised & $\begin{array}{l}\text { Multiple choice: } \\
\text { pictures }\end{array}$ & $\begin{array}{l}\text { After seeing each of the } \\
60 \text { NGT single sign video } \\
\text { clips on a computer screen, } \\
\text { the child selects one of } \\
4 \text { alternatives shown on } \\
\text { the screen. }\end{array}$ \\
\hline $\begin{array}{c}\text { Phonological } \\
\text { awareness-speech } \\
(\text { PhoSP) }\end{array}$ & Custom designed & $\begin{array}{l}\text { Number of correct } \\
\text { responses }\end{array}$ & Computerised & $\begin{array}{l}\text { Multiple choice: } \\
\text { pictures }\end{array}$ & $\begin{array}{l}\text { The child saw } 1 \text { picture at } \\
\text { the top of the screen and } \\
3 \text { other pictures at the } \\
\text { bottom. The child selected } \\
\text { the picture from the bottom } \\
\text { row that rhymed with the } \\
\text { top one. There were } \\
5 \text { practice and } 40 \text { test items. }\end{array}$ \\
\hline $\begin{array}{c}\text { Sign-based } \\
\text { phonological } \\
\text { awareness (PhoSL) }\end{array}$ & $\begin{array}{l}\text { Part of sign language } \\
\text { assessment battery } \\
\text { for elementary } \\
\text { school-aged children } \\
\text { (Hermans et al. 2007) }\end{array}$ & $\begin{array}{l}\text { Number of correct } \\
\text { responses }\end{array}$ & Computerised & $\begin{array}{l}\text { YES or NO. Both } \\
\text { spoken and signed } \\
\text { responses were } \\
\text { accepted }\end{array}$ & $\begin{array}{l}\text { Two signs were presented } \\
\text { simultaneously on a } \\
\text { computer screen. The two } \\
\text { signs are either identical or } \\
\text { overlap phonologically but } \\
\text { have a different hand shape, } \\
\text { location, orientation, } \\
\text { movement, or lip pattern. } \\
\text { The children indicated } \\
\text { whether the two signs were } \\
\text { the same or not. The test } \\
\text { contains } 36 \text { pairs of items, } \\
\text { half of which were identical } \\
\text { and half non-identical. }\end{array}$ \\
\hline
\end{tabular}


Table 1. Cont.

\begin{tabular}{|c|c|c|c|c|c|}
\hline Predictor & Source & $\begin{array}{l}\text { Dependent } \\
\text { Variable }\end{array}$ & Method & Response Type & Task Description \\
\hline $\begin{array}{l}\text { Fingerspelling } \\
\text { recognition (FSP) }\end{array}$ & Custom designed & $\begin{array}{l}\text { Number of correct } \\
\text { responses }\end{array}$ & $\begin{array}{l}\text { Computerised and } \\
\text { pen and paper }\end{array}$ & $\begin{array}{l}\text { Multiple choice: } \\
\text { printed words }\end{array}$ & $\begin{array}{l}\text { After seeing each of the } \\
26 \text { test fingerspelling } \\
\text { videos, the child selected } \\
\text { one of four possible printed } \\
\text { words on a piece of paper. } \\
\text { The presentation order was } \\
\text { fixed, and difficulty } \\
\text { increased as the test } \\
\text { progressed. }\end{array}$ \\
\hline $\begin{array}{l}\text { Short-term memory } \\
\text { (STM) }\end{array}$ & $\begin{array}{c}\text { Part of IQ assessment } \\
\text { battery for } \\
\text { elementary } \\
\text { school-aged children, } \\
\text { the RAKIT }\end{array}$ & $\begin{array}{l}\text { Number of correct } \\
\text { sequences recalled }\end{array}$ & $\begin{array}{l}\text { In-person with test } \\
\text { administrator }\end{array}$ & $\begin{array}{l}\text { Arrangement of the } \\
\text { objects on the table }\end{array}$ & $\begin{array}{l}\text { After seeing a sequence of } \\
\text { line-drawings depicting } \\
\text { objects for } 5 \text { seconds, the } \\
\text { child arranged the objects } \\
\text { on the table in the same } \\
\text { order. Difficulty increased } \\
\text { from 2-item sequences to } \\
7 \text {-item sequences. }\end{array}$ \\
\hline Word reading fluency & Custom designed & Accuracy and RTs & Computerised & $\begin{array}{l}\text { Word or } \\
\text { Pseudoword } \\
\text { decision in } \\
\text { computer }\end{array}$ & $\begin{array}{c}\text { Lexical decision over } \\
72 \text { letter strings ( } 36 \text { words) } \\
\text { 3-6 letter long and familiar } \\
\text { to children. }\end{array}$ \\
\hline Text reading fluency & CITO (Krom 2001) & $\begin{array}{l}\text { Number of items } \\
\text { answered correctly } \\
\text { relative to the total } \\
\text { number of items } \\
\text { responded to and } \\
\text { corrected for } \\
\text { guessing }\end{array}$ & Pen and paper & $\begin{array}{l}\text { Multiple choice: } \\
\text { printed words }\end{array}$ & $\begin{array}{c}\text { Presents a story } \\
\text { (approximately } 1000 \text { words } \\
\text { long). Around every } \\
10 \text { words the child selects } \\
\text { the correct word in that } \\
\text { location out of } \\
3 \text { orthographically similar } \\
\text { options. }\end{array}$ \\
\hline
\end{tabular}

Table 2. Overview of correlations between predictor variables for deaf children at time 1 with age partialled out.

\begin{tabular}{|c|c|c|c|c|c|c|c|c|c|c|c|c|}
\hline & & 1 & & 2 & & 3 & & 4 & & 5 & & 6 \\
\hline 1 & Vocabulary-Speech (VocSP) & - & & & & & & & & & & \\
\hline 2 & Vocabulary-Sign (VocSL) & 0.404 & $* *$ & - & & & & & & & & \\
\hline 3 & Phonological awareness Speech (PhoSP) & 0.585 & $* * *$ & 0.415 & *** & - & & & & & & \\
\hline 4 & Phonological awareness Sign (PhoSL) & 0.185 & & 0.287 & * & 0.413 & $* * *$ & - & & & & \\
\hline 5 & Fingerspelling (FSP) & 0.219 & & 0.383 & ** & 0.499 & $* * *$ & 0.265 & * & - & & \\
\hline 6 & Short-term memory (STM) & 0.241 & & 0.216 & & 0.351 & $* *$ & 0.142 & & 0.459 & $* * *$ & - \\
\hline
\end{tabular}

${ }^{* * *} p<0.001,{ }^{* *} p<0.01, * p<0.05$.

For the speech phonological awareness (PhoSP) test, 5 practice and 40 target pictures were selected from the Dutch Leesladder (Reading Ladder; Irausquin and Mommers 2001). The words associated with the pictures were all 1-syllable words with 3 to 6 letters (mean $=3.88$ letters). The mean log frequency for the words associated with the pictures was 1.63 (Baayen et al. 1993) and the mean number of orthographic neighbours was 17.88. The Cronbach's Alpha coefficient for the 40 test items was 0.91. In each trial, children saw a picture at the top of the screen accompanied by three other pictures at the bottom. Children were asked to select the picture from the bottom row that rhymed in Dutch with the object on the top row. The location of the target picture at the bottom was randomized across trials. Detailed feedback was given for the practice trials: after the child's answer, both the target and the selected picture moved to the left corner of the screen and their associated words were shown in either green (correct) or red (incorrect). To ensure understanding, the experimenter then repeated the feedback and the instructions. All children understood the task after the five practice trials. They could complete the remainder of the task at their own pace. The outcome measure used as a predictor in the current study was the number of correct responses. 
In the fingerspelling recognition test, videos of fingerspelled letter strings were presented one at the time on the screen. For each test item, four printed letter strings were then presented on a separate piece of paper and the child had to indicate which of the four strings was identical to the fingerspelled letter string. The test contained 26 items and gradually increased in difficulty from 2-letter strings to 8-letter strings. The mean length of the test items was 4.12 letters. The distracter strings differed from the target string in letter order, substitution or omission, or had no overlapping letters at all. The mean log frequency of the words was 2.03 (Baayen et al. 1993). Mean speech familiarity of the words among 6-year-old hearing children was $90.8 \%$ (Schaerlaekens et al. 1999). The Cronbach's Alpha coefficient of the 26 test items was 0.90 . The outcome measure used as a predictor in the current study was the number of correct responses.

\subsubsection{Dependent Measures}

Text reading fluency. The text reading fluency text (CITO) is routinely administered nationwide to hearing children at mid second grade, i.e., around 8 years of age (Krom 2001). Following the test instructions, the text reading fluency score was calculated as follows: number performed correctly * (number performed correctly - total number of items completed /3)/(total number of items completed - total number of items completed/3).

Word reading fluency. The word reading fluency task was specifically designed for this study. The children performed a lexical decision over 72 letter strings, half of which were real words and half pseudowords. The log frequency of the real word stimuli ranged from 1.11 to 3.53 (mean log frequency of 2.05) (Baayen et al. 1993); real word stimuli and pseudoword stimuli had an average of 16.03 (words) and 15.64 (pseudowords) orthographic neighbours (1 letter difference), respectively. To increase the likelihood that each of the words in the test was familiar to the children, the words were selected from a (spoken) lexical database for children and were familiar to at least $90 \%$ of hearing 6-year-old children (Schaerlaekens et al. 1999). In addition, the words occurred at least 10 times (out of 202.526 entries) in a database for written words in children's literature (Staphorsius et al. 1988). The word and pseudoword stimuli were between 3 and 6 letters long (mean length was 4.0 and 4.3 letters, respectively). Accuracy and reaction times were analysed as dependent variables.

Data analyses. A series of group comparisons were conducted to inform the subsequent regression analyses. First, a small group of children had a CI fitted at the time of testing. To test for possible differences in the performance between the deaf children with and without $\mathrm{CI}$, we ran separate independent samples $t$-tests for each of the dependent variables at T2 and T3. Second, we contrasted the performance of all deaf children for the dependent variables at T2 and T3 to scores from the group of age-matched hearing children attending the same school year to assess deaf children's performance relative to a group of typical readers. Third, we ran independent samples $t$-tests comparing year 3 and year 5 (at T1) children to check whether there were differences in the performance of deaf children depending on age at the time of testing. Based on the results from these $t$-tests (details below), all deaf children were treated as a single group independently of having a CI fitted or not. Furthermore, age was introduced as a first step in all regression analyses.

Stepwise linear regression analyses were conducted to identify possible predictors of word (accuracy and RTs) and text reading fluency (number correct out of total completed, corrected for guessing) of the deaf children at time 2 and time 3. For T2 performance analyses, T1 measures of age, spoken (VocSP) and signed (VocSL) receptive vocabulary, speech-based (PhoSP) and sign-based (PhoSL) phonological awareness, fingerspelling (FSP), and phonological short-term memory (STM) were introduced as predictor variables. Age was introduced in step one, followed by VocSP and VocSL in step two. The remaining variables were included in the third step to explore their unique contribution above and beyond age and vocabulary. PhoSP, PhoSL, FSP, and STM were introduced as the final step. Variables were retained in the model based on $p$-values. For T3 performance analyses, age was introduced in step one, followed by word reading accuracy and RTs at T2. Then, 
VocSP and VocSL were introduced to the model. Finally, to identify their possible unique contribution above and beyond age, performance at T2 and vocabulary, PhoSP, PhoSL, FSP, and STM were introduced in step four.

\section{Results}

Due to a technical issue, the word reading fluency data at $\mathrm{T} 2$ from two participants (one with and another one without CI) were not recorded. They were included in the study as all the other measures were collected.

\subsection{Influence of $C I$}

Independent samples $t$-tests showed that the deaf children with and without a CI did not perform significantly differently in word or text reading fluency assessment at $\mathrm{T} 2$ and $\mathrm{T} 3$ (all $p \mathrm{~s}>0.7$ ) and were therefore treated as a single group in all the analyses. Figure 2 shows the violin plots and $t$-test results for each of the study measures.

T2
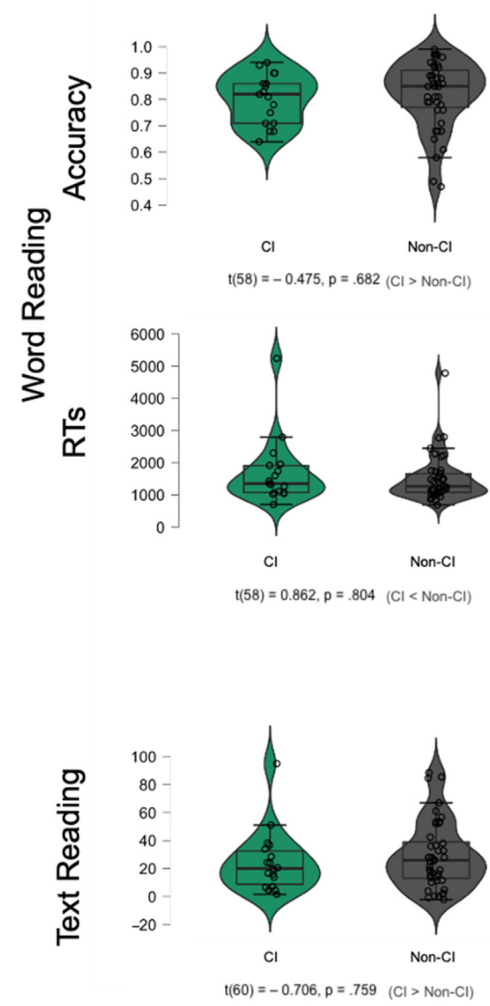

T3
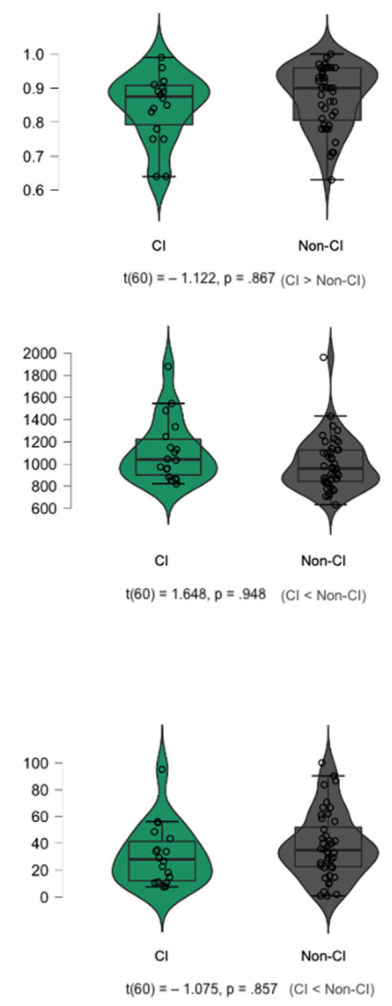

Figure 2. Response distributions and results from the independent sample $t$-tests for deaf children with and without $\mathrm{CI}$ at all the study measures.

\subsection{Deaf Children's Performance in Comparison to Age-Matched Hearing Children}

As expected, hearing children outperformed deaf children in both the word and the text reading fluency task at both T2 and T3. Details of these analyses can be found in Appendix B.

\subsection{Influence of Age}

Independent samples $t$-test comparing year 3 and year 5 deaf children's performance on the predictor variables collected at T1, and on word and text reading fluency measures at T2 and T3 showed that older children (year 5) outperformed younger children on all T1 measures (all $p s<0.008$; see Table 3 ). Older children also showed higher word and text reading accuracy at T2 and T3 (all $p s<0.001$. There were no significant differences in RTs in the word reading fluency test at either T2 or T3 (both $p \mathrm{~s}>0.9$ ). 
Table 3. Mean scores and statistical comparisons of year 3 (Y3) and year 5 (Y5) deaf children on predictor variables at time 1 , and word and text reading fluency at time 2 (T2) and time 3 (T3) and results of the independent samples $t$-tests comparing both groups. At time 1 (T1), year 3 children were approximately 8 years and year 5 children were approximately 10 years of age. Significant predictors are bolded.

\begin{tabular}{|c|c|c|c|c|c|c|c|c|c|}
\hline & & \multicolumn{2}{|c|}{ Y3 } & \multicolumn{2}{|c|}{ Y5 } & \multirow{2}{*}{ Difference } & \multirow{2}{*}{$\mathbf{t}$} & \multirow{2}{*}{ df } & \multirow{2}{*}{$p$} \\
\hline & & Mean & SD & Mean & SD & & & & \\
\hline \multirow{6}{*}{$\mathrm{T} 1$} & Vocabulary-Speech (VocSP) & 21 & 16 & 44 & 25 & -23 & -4.214 & 60 & $<.001$ \\
\hline & Vocabulary-Sign (VocSL) & 22 & 13 & 36 & 14 & -14 & -4.122 & 60 & $<.001$ \\
\hline & Phonological awareness Speech (PhoSP) & 22 & 7 & 31 & 6 & -9 & -5.294 & 60 & $<.001$ \\
\hline & Phonological awareness Sign (PhoSL) & 29 & 5 & 31 & 3 & -3 & -2.504 & 60 & .008 \\
\hline & Fingerspelling (FSP) & 18 & 5 & 23 & 3 & -5 & -4.581 & 60 & $<.001$ \\
\hline & Short term memory (STM) & 7 & 2 & 8 & 2 & -1 & -2.483 & 60 & .008 \\
\hline \multirow{3}{*}{$\mathrm{T} 2$} & Word reading accuracy & 75 & 12 & 88 & 8 & -12 & -4.647 & 58 & $<.001$ \\
\hline & Word reading $\mathrm{RTs}$ & 1696 & 754 & 1419 & 878 & 277 & 1.311 & 58 & .903 \\
\hline & Text reading & 17 & 18 & 38 & 23 & -20 & -3.819 & 60 & $<.001$ \\
\hline \multirow{3}{*}{ T3 } & Word reading accuracy & 82 & 9 & 91 & 7 & -9 & -4.055 & 60 & $<.001$ \\
\hline & Word reading RTs & 1108 & 298 & 965 & 193 & 143 & 2.256 & 60 & .986 \\
\hline & Text reading & 25 & 18 & 47 & 24 & -22 & -4.134 & 60 & $<.001$ \\
\hline
\end{tabular}

Based on these findings, age was added as a first step in the stepwise regression analyses to explore the effect of each of the predictors of children's reading performance beyond the effect of age.

\subsection{Predictors of Deaf Children's Reading Performance}

Correlations between predictors and dependent variables.

The correlations among the predictor variables and word and text reading performance for deaf children at time 2 and time 3 with age partialled out are shown in Figure 3. As can be seen, all the predictor variables showed a significant correlation $(p<0.05)$ with at least one of the dependent measures even after controlling for the variance linked to age. Therefore, all predictor variables were included in the stepwise regression analyses (see Cates et al. 2021 for a similar approach in a recent study with deaf adult readers).

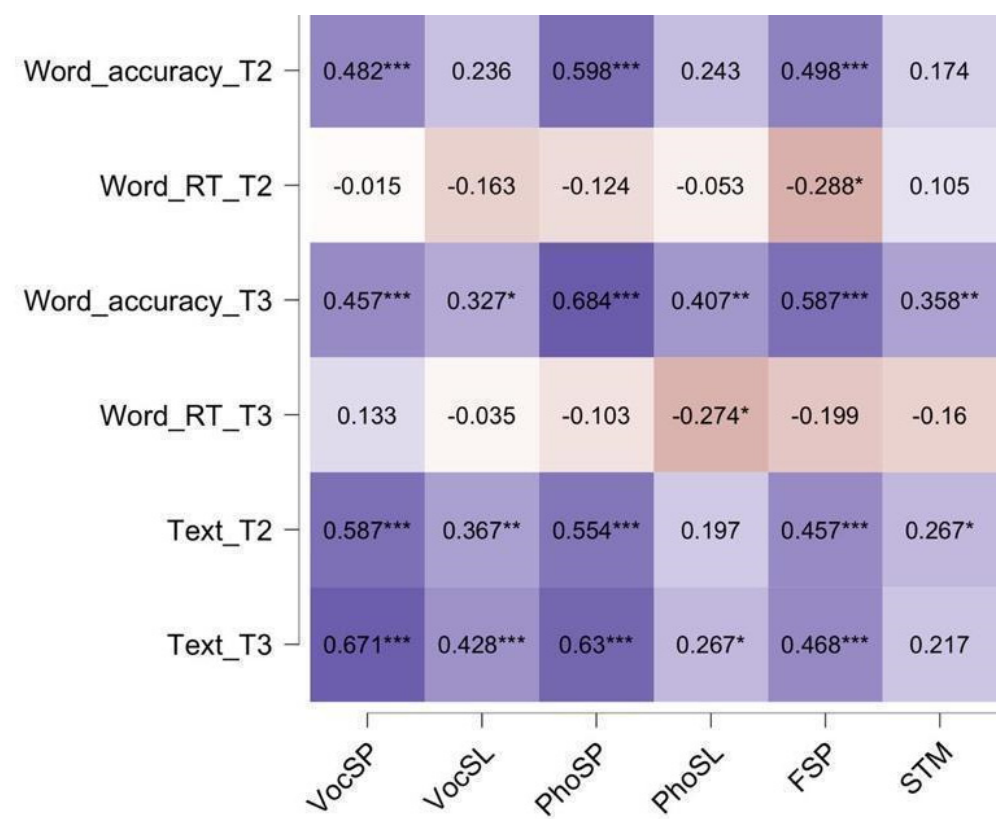

Figure 3. Correlation between predictors $(X$-axis) and dependent variables $(Y$-axis) with age partialled out. ${ }^{* *} p<.001,{ }^{* *} p<.01,{ }^{*} p<.05$. 


\subsection{Prediction of Word Reading Fluency at $\mathrm{T} 2$}

Word reading accuracy. In step 3 of the analysis, the variables age, VocSP, FSP, and PhoSP were entered into the regression equation, explaining $58 \%$ of the total variance of the accuracy of word reading at T2 (see Table 4 and Appendix C).

Table 4. Regression coefficients for word accuracy at T2. Significant predictors are bolded.

\begin{tabular}{|c|c|c|c|c|c|c|c|c|c|c|}
\hline & & \multirow[b]{2}{*}{ B } & \multirow[b]{2}{*}{$\begin{array}{l}\text { Std. } \\
\text { Error }\end{array}$} & \multirow[b]{2}{*}{ Beta } & \multicolumn{6}{|c|}{$95.0 \% \mathrm{CI}$} \\
\hline & & & & & $t$ & $p$ & LB & UB & Tolerance & VIF \\
\hline \multirow[t]{2}{*}{1} & (Constant) & 0.335 & 0.112 & & 2.981 & .004 & 0.110 & 0.560 & & \\
\hline & Age & 0.004 & 0.001 & 0.492 & 4.302 & $<.001$ & 0.002 & 0.007 & 1.000 & 1.000 \\
\hline \multirow[t]{3}{*}{2} & (Constant) & 0.489 & 0.106 & & 4.617 & $<.001$ & 0.277 & 0.701 & & \\
\hline & Age & 0.002 & 0.001 & 0.254 & 2.190 & .033 & 0.000 & 0.004 & 0.758 & 1.320 \\
\hline & Vocabulary-Speech (VocSP) & 0.002 & 0.001 & 0.483 & 4.159 & $<.001$ & 0.001 & 0.003 & 0.758 & 1.320 \\
\hline \multirow[t]{4}{*}{3} & (Constant) & 0.458 & 0.095 & & 4.817 & $<.001$ & 0.268 & 0.648 & & \\
\hline & Age & 0.001 & 0.001 & 0.089 & 0.798 & .428 & -0.001 & 0.003 & 0.650 & 1.538 \\
\hline & Vocabulary-Speech (VocSP) & 0.002 & 0.001 & 0.395 & 3.723 & $<.001$ & 0.001 & 0.003 & 0.724 & 1.381 \\
\hline & Fingerspelling (FSP) & 0.010 & 0.003 & 0.416 & 3.906 & $<.001$ & 0.005 & 0.015 & 0.718 & 1.393 \\
\hline \multirow[t]{5}{*}{4} & (Constant) & 0.455 & 0.092 & & 4.965 & $<.001$ & 0.272 & 0.639 & & \\
\hline & Age & 0.000 & 0.001 & 0.054 & 0.498 & .620 & -0.001 & 0.002 & 0.637 & 1.569 \\
\hline & Vocabulary-Speech (VocSP) & 0.001 & 0.001 & 0.236 & 1.900 & .063 & 0.000 & 0.002 & 0.493 & 2.029 \\
\hline & Fingerspelling (FSP) & 0.007 & 0.003 & 0.294 & 2.526 & .014 & 0.001 & 0.012 & 0.562 & 1.778 \\
\hline & $\begin{array}{l}\text { Phonological awareness } \\
\text { Speech (PhoSP) }\end{array}$ & 0.005 & 0.002 & 0.326 & 2.271 & .027 & 0.001 & 0.009 & 0.368 & 2.718 \\
\hline
\end{tabular}

Word reading latency. In step 2 of the analysis, the variables FSP and STM were entered into the regression equation, explaining $15.8 \%$ of the total variance (see Table 5 and Appendix C).

Table 5. Regression coefficients for word RTs at T2. Significant predictors are bolded.

\begin{tabular}{|c|c|c|c|c|c|c|c|c|c|c|}
\hline & & \multirow[b]{2}{*}{ B } & \multirow[b]{2}{*}{ Std. Error } & \multirow[b]{2}{*}{ Beta } & \multicolumn{6}{|c|}{$95 \%$ CI } \\
\hline & & & & & $t$ & $p$ & LB & UB & Tolerance & VIF \\
\hline \multirow[t]{2}{*}{1} & (Constant) & 2758.122 & 436.987 & & 6.312 & $<.001$ & 1883.398 & 3632.846 & & \\
\hline & Fingerspelling (FSP) & -57.182 & 2.251 & -0.348 & -2.824 & .006 & -97.719 & -16.645 & 1.000 & 1.000 \\
\hline \multirow[t]{3}{*}{2} & (Constant) & 2551.981 & 434.910 & & 5.868 & $<.001$ & 1681.089 & 3422.873 & & \\
\hline & Fingerspelling (FSP) & -86.077 & 23.847 & -0.523 & -3.610 & .001 & -133.829 & -38.324 & 0.679 & 1.472 \\
\hline & STM & 11.353 & 51.579 & 0.310 & 2.140 & .037 & 7.068 & 213.637 & 0.679 & 1.472 \\
\hline
\end{tabular}

\subsection{Prediction of Word Reading Fluency at T3}

Word reading accuracy. In step 4 of the analysis the variables age, word fluency accuracy at T2, PhoSP, and FSP were entered into the regression equation, explaining $78 \%$ of the total variance (see Table 6 and Appendix C).

Word reading latency. In step 2 of the analysis, the variables age and PhoSL were entered into the regression equation, explaining $16.2 \%$ of the total variance (see Table 7 and Appendix C).

To summarize, age, speech-based vocabulary, fingerspelling, and phonological awareness of speech were predictive of word reading fluency at time 2. One year later, age, speech-based vocabulary, fingerspelling, and phonological awareness of speech were still predictive of word reading accuracy while only sign-based phonological awareness was predictive of word reading latency of responses at $\mathrm{T} 3$. 
Table 6. Regression coefficients for word accuracy at T3. Significant predictors are bolded.

\begin{tabular}{|c|c|c|c|c|c|c|c|c|c|c|}
\hline & & \multirow[b]{2}{*}{ B } & \multirow[b]{2}{*}{ Std. Error } & \multirow[b]{2}{*}{ Beta } & \multicolumn{6}{|c|}{$95.0 \% \mathrm{CI}$} \\
\hline & & & & & $t$ & $p$ & LB & UB & Tolerance & VIF \\
\hline \multirow[t]{2}{*}{1} & (Constant) & 0.495 & 0.092 & & 5.387 & $<.001$ & 0.311 & 0.679 & & \\
\hline & Age & 0.003 & 0.001 & 0.471 & 4.072 & $<.001$ & 0.002 & 0.005 & 1.000 & 1.000 \\
\hline \multirow[t]{3}{*}{2} & (Constant) & 0.279 & 0.061 & & 4.558 & $<.001$ & 0.156 & 0.401 & & \\
\hline & Age & 0.001 & 0.001 & 0.079 & 0.953 & .345 & -0.001 & 0.002 & 0.758 & 1.319 \\
\hline & Word accuracy T2 & 0.645 & 0.067 & 0.799 & 9.689 & $<.001$ & 0.512 & 0.779 & 0.758 & 1.319 \\
\hline \multirow[t]{4}{*}{3} & (Constant) & 0.373 & 0.062 & & 6.027 & $<.001$ & 0.249 & 0.496 & & \\
\hline & Age & 0.000 & 0.001 & -0.007 & -0.087 & .931 & -0.001 & 0.001 & 0.687 & 1.456 \\
\hline & Word accuracy T2 & 0.485 & 0.076 & 0.601 & 6.396 & $<.001$ & 0.333 & 0.637 & 0.487 & 2.055 \\
\hline & $\begin{array}{l}\text { Phonological awareness } \\
\text { Speech (PhoSP) }\end{array}$ & 0.004 & 0.001 & 0.342 & 3.530 & .001 & 0.002 & 0.006 & 0.458 & 2.184 \\
\hline \multirow[t]{5}{*}{4} & (Constant) & 0.381 & 0.060 & & 6.344 & $<.001$ & 0.260 & 0.501 & & \\
\hline & Age & 0.000 & 0.001 & -0.041 & -0.519 & .606 & -0.001 & 0.001 & 0.660 & 1.516 \\
\hline & Word accuracy T2 & 0.437 & 0.077 & 0.541 & 5.686 & $<.001$ & 0.283 & 0.591 & 0.445 & 2.245 \\
\hline & $\begin{array}{l}\text { Phonological awareness } \\
\text { Speech (PhoSP) }\end{array}$ & 0.003 & 0.001 & 0.283 & 2.894 & .005 & 0.001 & 0.006 & 0.422 & 2.369 \\
\hline & Fingerspelling (FSP) & 0.004 & 0.002 & 0.190 & 2.159 & .035 & 0.000 & 0.007 & 0.521 & 1.920 \\
\hline
\end{tabular}

Table 7. Regression coefficients for word RTs at T3. Significant predictors are bolded.

\begin{tabular}{|c|c|c|c|c|c|c|c|c|c|c|}
\hline & & \multirow[b]{2}{*}{ B } & \multirow[b]{2}{*}{$\begin{array}{l}\text { Std. } \\
\text { Error }\end{array}$} & \multirow[b]{2}{*}{ Beta } & \multicolumn{6}{|c|}{$95.0 \% \mathrm{CI}$} \\
\hline & & & & & $t$ & $p$ & LB & UB & Tolerance & VIF \\
\hline \multirow[t]{2}{*}{1} & (Constant) & 1696.88 & 272.300 & & 6.232 & $<.001$ & 1151.81 & 2241.95 & & \\
\hline & Age & -6.140 & 2.517 & -0.305 & -2.439 & .018 & -11.178 & -1.102 & 1.000 & 1.000 \\
\hline \multirow[t]{3}{*}{2} & (Constant) & 2025.96 & 304.924 & & 6.644 & $<.001$ & 1415.37 & 2636.57 & & \\
\hline & Age & -4.449 & 2.564 & -0.221 & -1.736 & .088 & -9.583 & 0.684 & 0.907 & 1.103 \\
\hline & $\begin{array}{l}\text { Phonological awareness Sign } \\
\text { (PhoSL) }\end{array}$ & -17.004 & 7.876 & -0.275 & -2.159 & .035 & -32.776 & -1.233 & 0.907 & 1.103 \\
\hline
\end{tabular}

\subsection{Prediction of Text Reading Fluency at $T 2$}

In step 3 of the analysis, the variables age, VocSP, and FSP were entered into the regression equation, which explained $56 \%$ of the total variance (see Table 8 and Appendix C).

Table 8. Regression coefficients for text fluency at T2. Significant predictors are bolded.

\begin{tabular}{|c|c|c|c|c|c|c|c|c|c|c|}
\hline & & \multirow[b]{2}{*}{ B } & \multirow[b]{2}{*}{$\begin{array}{l}\text { Std. } \\
\text { Error }\end{array}$} & \multirow[b]{2}{*}{ Beta } & \multicolumn{6}{|c|}{$95.0 \% \mathrm{CI}$} \\
\hline & & & & & $t$ & $p$ & LB & UB & Tolerance & VIF \\
\hline \multirow[t]{2}{*}{1} & (Constant) & -56.420 & 22.536 & & -2.504 & .015 & -101.500 & -11.341 & & \\
\hline & Age & 0.782 & 0.207 & 0.437 & 3.767 & $<.001$ & 0.367 & 1.197 & 1.000 & 1.000 \\
\hline \multirow[t]{3}{*}{2} & (Constant) & -21.561 & 19.439 & & -1.109 & .272 & -60.458 & 17.337 & & \\
\hline & Age & 0.282 & 0.192 & 0.158 & 1.472 & .146 & -0.101 & 0.666 & 0.781 & 1.280 \\
\hline & Vocabulary-Speech (VocSP) & 0.579 & 0.104 & 0.597 & 5.566 & $<.001$ & 0.371 & 0.787 & 0.781 & 1.280 \\
\hline \multirow[t]{4}{*}{3} & (Constant) & -27.370 & 17.908 & & -1.528 & .132 & -63.217 & 8.477 & & \\
\hline & Age & 0.032 & 0.190 & 0.018 & 0.169 & .866 & -0.348 & 0.412 & 0.669 & 1.494 \\
\hline & Vocabulary-Speech (VocSP) & 0.505 & 0.098 & 0.520 & 5.159 & $<.001$ & 0.309 & 0.700 & 0.744 & 1.345 \\
\hline & Fingerspelling (FSP) & 1.674 & 0.481 & 0.357 & 3.483 & .001 & 0.712 & 2.636 & 0.721 & 1.388 \\
\hline
\end{tabular}

\subsection{Prediction of Text Reading Fluency at TIME 3}

In step 3 of the analysis, the variables age, word fluency accuracy at T2, VocSP, and FSP were entered into the regression equation, explaining $68 \%$ of the total variance (see

Table 9 and Appendix C). 
Table 9. Regression coefficients for text fluency at T3. Significant predictors are bolded.

\begin{tabular}{|c|c|c|c|c|c|c|c|c|c|c|}
\hline & & \multirow[b]{2}{*}{ B } & \multirow[b]{2}{*}{$\begin{array}{l}\text { Std. } \\
\text { Error }\end{array}$} & \multirow[b]{2}{*}{ Beta } & \multicolumn{6}{|c|}{$95.0 \% \mathrm{CI}$} \\
\hline & & & & & $T$ & $p$ & LB & UB & Tolerance & VIF \\
\hline \multirow[t]{2}{*}{1} & (Constant) & -61.631 & 23.326 & & -2.642 & .011 & -108.323 & -14.940 & & \\
\hline & Age & 0.913 & 0.216 & 0.486 & 4.237 & $<.001$ & 0.482 & 1.345 & 1.000 & 1.000 \\
\hline \multirow[t]{3}{*}{2} & (Constant) & -103.854 & 20.078 & & -5.172 & $<.001$ & -144.060 & -63.648 & & \\
\hline & Age & 0.350 & 0.198 & 0.186 & 1.765 & .083 & -0.047 & 0.748 & 0.758 & 1.319 \\
\hline & Word accuracy T2 & 126.107 & 21.861 & 0.609 & 5.769 & $<.001$ & 82.331 & 169.884 & 0.758 & 1.319 \\
\hline \multirow[t]{4}{*}{3} & (Constant) & -55.885 & 20.034 & & -2.790 & .007 & -96.018 & -15.753 & & \\
\hline & Age & 0.119 & 0.177 & 0.064 & 0.674 & .503 & -0.235 & 0.474 & 0.699 & 1.431 \\
\hline & Word accuracy T2 & 78.020 & 21.370 & 0.377 & 3.651 & .001 & 35.210 & 12.830 & 0.582 & 1.719 \\
\hline & Vocabulary-Speech (VocSP) & 0.484 & 0.104 & 0.482 & 4.664 & $<.001$ & 0.276 & 0.691 & 0.581 & 1.721 \\
\hline \multirow[t]{5}{*}{4} & (Constant) & -47.228 & 19.622 & & -2.407 & .019 & -86.553 & -7.904 & & \\
\hline & Age & 0.001 & 0.178 & 0.001 & 0.008 & .993 & -0.354 & 0.357 & 0.643 & 1.555 \\
\hline & Word accuracy T2 & 52.835 & 23.190 & 0.255 & 2.278 & .027 & 6.361 & 99.309 & 0.457 & 2.188 \\
\hline & Vocabulary-Speech (VocSP) & 0.493 & 0.100 & 0.491 & 4.935 & $<.001$ & 0.293 & 0.693 & 0.580 & 1.723 \\
\hline & Fingerspelling (FSP) & 1.153 & 0.491 & 0.237 & 2.347 & .023 & 0.169 & 2.137 & 0.564 & 1.773 \\
\hline
\end{tabular}

To summarize, age, speech-based vocabulary, and fingerspelling proved to be the strongest predictors of text reading fluency at both T2 and T3 (as expected, word reading fluency at T2 explained additional variance in text reading fluency at T3).

\section{General Discussion}

The current study investigated the predictive value of receptive speech- and sign-based vocabularies, speech and signed-based phonological awareness, fingerspelling ability, and STM on word and text reading fluency in deaf children in bilingual education programmes in year $3(\sim 8$ years old) and year $5(\sim 10$ years old) across a time-span of 2 years. A small subgroup of children in these programmes wore a $\mathrm{CI}$ at the time of the study. A group of age-matched hearing children also completed the word and text reading fluency tasks at T2 and T3 to evaluate deaf children's performance against norms for their peers with normal hearing. We found that (1) speech-based vocabulary predicted word reading accuracy and text reading fluency both at T2 and T3, (2) fingerspelling ability was a strong predictor of word and text reading fluency at both T2 and T3, (3) speech-based phonological awareness predicted word reading accuracy at $\mathrm{T} 2$ and $\mathrm{T} 3$ but did not predict text reading fluency, and (4) fingerspelling and STM predicted word reading latency at T2 while sign-based phonological awareness predicted this outcome measure at T3.

In line with most previous research, deaf children obtained lower text reading fluency scores and word reading accuracy than hearing children at both T2 and T3. However, word reading latencies at T2 and T3 were similar for deaf and hearing children (see Appendix B for details). Finally, there were no differences in the performance between the deaf children without CI and the small group of children with CI. In the rest of this section, we will discuss each of these findings.

\subsection{Speech-Based Vocabulary, Fingerspelling, and Speech-Based Phonological Awareness Predict Reading Accuracy}

Our finding that vocabulary is a strong predictor of word and text reading abilities in deaf children in bimodal bilingual education in the current study provides new evidence in favour of the simple view of reading for deaf readers (Gough and Tunmer 1986; Chamberlain and Mayberry 2000). Within this theory of reading development, word decoding and linguistic comprehension are the two necessary components for successful reading acquisition. Loading strongly on the linguistic comprehension component, vocabulary has consistently been identified as the strongest predictor of reading in deaf children and adults (see, e.g., Wauters et al. 2021; Cates et al. 2021). As discussed in the introduction, previous work had either measured only speech-based receptive vocabulary (e.g., Moreno-Pérez 
et al. 2015) or had measured expressive vocabulary, allowing children to respond in their spoken language, their sign language, or a combination of both (e.g., Kyle et al. 2016). Measuring expressive vocabulary as a whole also makes sense in light of findings that receptive and expressive vocabularies have loaded into a single language factor in hearing children (see e.g., Anthony et al. 2014; Bornstein et al. 2014). However, it does not allow assessment of each language separately. Assessing receptive vocabulary in both language modalities enables us to explore the unique contribution of speech-based and sign-based vocabularies. We found that despite being positively correlated to speech-based vocabulary $(\mathrm{r}=0.404, p<0.01)$, signed-based vocabulary did not predict word or text reading fluency in the current study. This suggests a stronger link of early reading abilities with spoken than signed vocabulary for the deaf children in bimodal bilingual education in the current study.

At first sight, this result seems inconsistent with the findings of one of the few previous studies of literacy outcomes in deaf children in bilingual education. Scott and Hoffmeister (2016) studied deaf children attending middle- and high-school (years 6 to 12) classes at deaf bilingual schools in North America. Their results showed that SL proficiency was the stronger predictor of reading comprehension. Interestingly, the authors also found evidence of a stronger impact of English proficiency on reading comprehension at lower levels of word reading fluency. Therefore, it is possible that our findings reflect an earlier stage in reading development when linguistic knowledge might hold a heavier weight in explaining reading comprehension. The correlations that we observed between SL vocabulary and each of the dependent variables (Figure 3) seem consistent with this interpretation. Specifically, we observed a small positive correlation between signed-based vocabulary and text reading fluency at T2 $(\mathrm{r}=367, p<0.01)$ but a moderate correlation at T3 $(r=0.428, p<0.001)$, suggesting a stronger relationship at later stages of development. In a similar vein, DeLana et al. (2007) found a correlation between reading achievement and number of years using SL. However, the existing knowledge base is small, with many methodological differences between studies. Future studies should establish whether this suggested developmental pattern can also be shown in a comprehensive longitudinal study, where other important factors are controlled for. In a review of a small number of available studies, Mayer and Trezek (2020) propose that, together with the use of hearing aids or CIs, initial signed and spoken language proficiency are important factors to control for in studies of reading abilities with deaf children. We also acknowledge that, while the children in the current study were regularly exposed to NGT in the classroom, teachers' level of NGT proficiency varied and detailed information on the quantity and quality of their bilingual input was not available. These are important factors to consider in future studies of the relation between sign language proficiency and reading performance in deaf children. In addition, it is possible that the strong inter-correlations between the different predictor variables observed here reflect common specific teaching practices in the Netherlands (see below), such as explicitly linking written words, signs, fingerspellings, and-sometimesmouth patterns to improve deaf children's knowledge of written words (Hermans et al. 2007). Future studies could describe the extent to which practices, such as chaining, are in fact used in the classroom and how these relate to children's reading outcomes. In summary, the present study highlights the utility of assessing both speech- and sign-based linguistic comprehension in studies of reading development in deaf children to disentangle their unique contributions to reading development and the complex relationships between both languages at different linguistic levels.

We would like to point out here again that the test administrator pronounced each of the words while in clear view of the child, allowing the deaf children to rely on visual speech information to complete this test. Although we did not measure speechreading ability separately, a previous study using a very similar assessment of receptive vocabulary (Moreno-Pérez et al. 2015) only found a moderate correlation with speechreading ability $(\mathrm{r}=0.37, p=0.006)$. The moderate correlation suggests that an assessment of receptive vocabulary measures more than just speechreading ability. The extent to which speech-based vocabulary is linked to speechreading ability — as an important channel through which 
many deaf children acquire speech-based vocabulary-is a question that future research should address. This might be especially relevant for deaf readers, as speechreading ability has also been proposed to play an important role in enhancing phonological knowledge in deaf readers (Buchanan-Worster et al. 2020; Kyle et al. 2016). Future research could also examine whether a picture-based receptive vocabulary task may show stronger correlations with the reading performance of deaf children than the format with printed words used in the current study.

While speech-based phonological awareness predicted word reading accuracy at T2 and T3, it did not predict text reading fluency at either T2 or T3. This result contrasts with studies in hearing children finding that phonological decoding and reading comprehension are related at all ages across development (see García and Cain 2014 for a recent metaanalysis). However, our finding is consistent with previous research showing a limited role for phonological awareness in some studies of reading development in deaf children (e.g., dependent on their language background and CI use), and studies suggesting that vocabulary might be a stronger predictor of reading comprehension for deaf children than hearing children (Mayberry et al. 2011; Moreno-Pérez et al. 2015; Kyle et al. 2016). Dutch, as Spanish or Italian, is considered to have a transparent orthography. The consistent correspondence between graphemes and phonemes in transparent orthographies might facilitate readers' access to phonological information from words during word recognition (Katz and Frost 1992). However, in the case of deaf readers, the use of phonological codes from words during word recognition might not be associated with better reading comprehension. A recent study with adult deaf readers of Spanish (Gutierrez-Sigut et al. 2017) showed clear activation of phonological codes in behavioural and electrophysiological responses during word recognition. However, the size of the phonological effects was not correlated with reading comprehension in deaf readers, suggesting that deaf readers might more strongly rely on other linguistic abilities in reading comprehension. For example, recent research in adult deaf readers suggests that visual and orthographic factors might play a more important role in deaf people's reading comprehension (e.g., Emmorey et al. 2021; Gutierrez-Sigut et al. 2019, 2022). The present findings suggest that the contribution of speech phonology to reading comprehension is also limited even during early stages of reading acquisition in some groups of deaf children. However, much more research is needed to fully understand how much, what type, and at which stages phonological knowledge of speech is needed or beneficial for reading development in different groups of deaf children.

Sign-based phonological awareness only predicted word reading latencies at T3. This result seems consistent with the findings by Ormel et al. (2012) that deaf children are sensitive to phonological information in sign translation equivalents of Dutch words during visual word recognition. Similar results have been found in deaf teenagers (Villwock et al. 2021) and deaf adult readers (Morford et al. 2011, 2017). This result is also in line with other recent studies showing positive correlations between sign language knowledge and reading abilities (Scott and Hoffmeister 2016; Crume et al. 2021; Keck and Wolgemuth 2020; Holmer et al. 2016). It remains unclear, however, why this variable only impacted word reading fluency at $\mathrm{T} 3$ and why it only affected word reading latency, not accuracy or text reading fluency. Nevertheless, this is an intriguing result that highlights the importance of including sign-based linguistic measures in reading studies involving deaf children who sign, and more research on the potential role of sign-based phonological awareness in reading acquisition for deaf children in bimodal bilingual education is required.

A final key finding of the present experiment was the strong predictive power of fingerspelling. Although only a handful of studies to date have investigated the role of fingerspelling in the reading development of deaf children (e.g., Haptonstall-Nykaza and Schick 2007; Miller et al. 2021), it appears to be strongly related to reading abilities in deaf children and adults (e.g., Padden 2006; Miller et al. 2015; Stone et al. 2015; Sehyr et al. 2016). Fingerspelling might be an important skill for deaf children to support reading acquisition because the mapping between fingerspelled handshapes onto letters may 
facilitate orthographic segmentation and word decoding. This seems in line with recent findings from an ERP study by Emmorey et al. (2017), who found less differentiated N170 responses to written words (relative to symbol strings) in skilled adult deaf readers than adult hearing readers, suggesting differential neural tuning to print for deaf readers. It should be noted that, although fingerspelling was not correlated with speech-based vocabulary in the current study, it was positively correlated with sign vocabulary and both speech- and sign-based phonological awareness. This pattern of correlations seems consistent with the view that the manual-visual component of fingerspelling can provide a bridge between signs on the one hand and written word forms on the other hand.

Although the underlying mechanism is still unclear, fingerspelling may tap into phonological or orthographic processing. A number of researchers have conceptualized the role of fingerspelling as a link between the printed words and their phonological representations (e.g., Haptonstall-Nykaza and Schick 2007; Sehyr et al. 2016). For example, fingerspelling might provide phonological or prosodic information about words through cadence of movement and therefore contribute to more robust phonological-lexical representations (Haptonstall-Nykaza and Schick 2007). The above-mentioned correlation between speechbased phonological awareness and fingerspelling ability supports this view. Furthermore, in hearing children, it is commonly accepted that phonology stabilises letter representations and makes orthographic processing and orthography-to-meaning mappings more efficient. Given the underspecified phonological access and knowledge for many deaf children, it is possible that fingerspelling can take on this role of stabilising letter representations. Stone et al. (2015) hypothesise that fingerspelling strengthens (printed) word decoding accuracy and word recognition automaticity through shared underlying processes with visual orthographic processing (e.g., perceiving and decoding sequences of letter representations). In contrast, Miller et al. (2021) proposed that fingerspelling might link to orthographic learning independently of phonological skill. Finally, it is possible that fingerspelling enriches representations of written letters through a motor component ('embodied letters'), in the same way as number gestures have been argued to support the acquisition of (stable) symbolic number representations in hearing children (e.g., Di Luca and Pesenti 2011; Fischer 2012). The present results confirm the important role of fingerspelling in the reading acquisition of deaf bimodal bilingual children. However, further research is needed aimed specifically at investigating the specific role of fingerspelling and its relationship to both phonological and orthographic knowledge.

\subsection{Different Predictors for Reading Latencies vs. Accuracy}

Fingerspelling and STM explained some of the variance in the word reading latencies at T2 while sign-based phonological awareness accounted for some of the variance at T3. Here, we observed a positive correlation between STM and both speech-based phonological awareness and fingerspelling. However, as in previous studies (Kyle and Harris 2006; Waters and Doehring 1990), we did not find evidence for a strong relationship between STM and word or text reading accuracy. Previous research shows that children with good STM skills also tend to have good phonological skills and, conversely, phonological encoding can enhance STM performance (Alloway et al. 2005; Marschark et al. 2002). Some researchers have therefore suggested that STM only plays a role in reading development to the extent that phonological skills do (Durand et al. 2005). Given the limited contribution of speech-based phonological awareness to the word and text reading abilities of the deaf children in the current study, it may therefore not be surprising that we also found a limited role for STM.

It is important to note that the variance in the word and text reading accuracy in the current study was explained relatively well by the factors included in the stepwise regression analysis. In contrast, although fingerspelling, STM, and sign-based phonological awareness accounted for some of the variance in word reading latencies at T2 or T3, these factors explained less variance than for word reading accuracy. One possible explanation is that word reading latency is also-or even more so-influenced by other factors, for exam- 
ple, factors related to visual and/or orthographic processing. Several studies have found similar or even faster word reading latencies for deaf readers compared to hearing readers, sometimes in combination with lower accuracy levels (e.g., Fariña et al. 2017; Hanson and Fowler 1987; Morford et al. 2017). Similarly, recent studies showed stronger identity priming effects in adult deaf vs. hearing readers (Gutierrez-Sigut et al. 2017; Gutierrez-Sigut et al. 2018), so-called 'hyperpriming'. To account for such findings, Bélanger and Rayner (2015) proposed the 'word-processing efficiency hypothesis', which stipulates that skilled deaf readers are more "efficient" than hearing readers at processing written words because they bypass phonological codes and therefore have stronger connections between orthography and semantics, and because they are strongly attuned to the visual-orthographic makeup of words. Since word recognition speed is important for fluent reading, future studies should investigate the predictive contribution of visual/orthographic processing measures in explaining the variance in the word and text reading fluency of deaf children.

\subsection{Word and Text Reading in Deaf Children with and without $\mathrm{CI}$}

Cochlear implants (CIs) provide increased access to speech for many deaf children, often improving spoken language development (e.g., De Raeve 2010; Marschark et al. 2007; Vermeulen et al. 2007). This improvement in spoken language skills, together with the wider availability of early implantation worldwide, has favoured educational policies where implanted children attend mainstream education (see, e.g., Langereis and Vermeulen 2011). However, having a CI, even if fitted early (i.e., before 24 months), does not guarantee reading levels comparable to hearing peers. While some studies have found that children with CI read at an age-appropriate level (see, e.g., Archbold et al. 2008; Mayer et al. 2016), other research has found that word decoding, reading comprehension, and readingrelated skills, such as vocabulary, phonological awareness, and speechreading ability, are comparable between children with CIs and deaf children with hearing aids (e.g., Harris et al. 2017).

Reading performance for the subgroup of children with a CI in the current study did not differ from the deaf children without a CI. However, it is important to keep in mind that these children attended a bimodal bilingual education programme and were not in mainstream education or schools for the deaf with more emphasis on spoken language. In addition, the children in the present study were born before universal hearing screening was in place and had their implant fitted after two years of age, which is much later than deaf children in many countries (including the Netherlands) nowadays. There is a growing body of research indicating that children implanted under 24 months of age can match the progress of normally hearing peers in some areas of language development (Schauwers et al. 2004; De Raeve 2010). Moreover, CI technology has significantly advanced over the years, including possibilities for bilateral implantation. This finding therefore should not be generalised to deaf children whose hearing loss is diagnosed soon after birth and receive implants within the first year of life. At the same time, it is important to keep in mind that there are many countries where (early) implantation is not yet common practice early during development for deaf children (see Knoors et al. 2019 for an overview). Moreover, over two decades of research of language outcomes in deaf children with CIs shows that, despite increased access to the spoken language and on average positive results on speech perception and vocabulary, reading outcomes of children with CIs are highly variable and often remain below the level of hearing children of the same age.

\subsection{Relation with Bimodal Bilingual Educational Practices}

The implementation of bilingual deaf education in the Netherlands in 1998 resulted in the development of national frameworks and bilingual curricula were developed for Sign Language of the Netherlands (SLN), spoken and written Dutch, and for reading instruction, including web-based multi-modal reading materials (Reading Miles programme; de Klerk et al. 2015). Not expecting automatic transfer of language proficiency between spoken Dutch and SLN (see, e.g., Mayer and Wells 1996; Hermans et al. 2008a), schools for the 
deaf explicitly stimulated links between the various representations of concepts, such as signs, fingerspelling, written, and spoken words. Didactic strategies, such as chaining and sandwiching (Padden and Ramsey 2000), were used and spoken vocabulary training explicitly linking signs and spoken words was introduced, following insights from research in sign and spoken word processing in deaf children (Giezen et al. 2014) and other previous research showing that these didactic practices led to a significant association of written and sign vocabulary (Hermans et al. 2008b; Hoffmeister 2000; Strong and Prinz 2000) and to improved spoken word learning (van Berkel-van Hoof et al. 2016; Hermans et al. 2021). Didactic coaching of teachers facilitated implementation of these reading strategies by teachers in the classroom. Research results showed that teacher coaching using video-feedback was especially promising (Wauters and de Klerk 2014). Our results, particularly the strong predictive power of fingerspelling, likely reflect these explicit educational practices. These practices may stimulate representational knowledge of print and cross-linguistic transfer between the signed and written language modality similar to research showing positive effects of bilingualism and bilingual education on literacy development in hearing children (see, e.g., Bialystok 2018; Baker et al. 2016 for reviews). However, it should be emphasized that it is unclear from the current results, whether our findings reflect to what extent specific bilingual education practices exercised in the bimodal bilingual classroom resulted in dual language acquisition of signed and written language abilities.

To conclude, speech-based vocabulary and fingerspelling might be the main contributors to reading acquisition in deaf children in bimodal bilingual education, although other factors, such as STM and sign-based phonological awareness, might affect word reading speed at later stages. Speech-based phonological awareness seems to have a more limited role in reading development for these children compared to their hearing peers. Altogether, our results support the use of fingerspelling as an effective tool to support printed word decoding by linking the signs and the sublexical (orthographic and phonological) representations of words. Finally, we would like to stress the importance of more research into sign- and speech-related contributors to reading acquisition in fully bimodal bilingual co-enrollment programmes that are implemented in an increasing number of places across the globe (e.g., Hong Kong, Brisbane, Toronto), where deaf and hearing children attend school together and signed and spoken languages are assigned an equal educational role in the classroom, involving deaf and hearing teachers as role models in the school (Tang et al. 2014).

Author Contributions: Conceptualization, E.O., H.K. and L.V.; methodology, E.O. and M.R.G.; formal analysis, E.O., M.R.G. and E.G.-S.; investigation, E.O., M.R.G. and E.G.-S.; data curation, E.O.; writing-original draft preparation, E.O. and E.G.-S.; supervision, H.K. and L.V. All authors have read and agreed to the published version of the manuscript.

Funding: This research received no external funding.

Institutional Review Board Statement: The study was conducted in accordance with the Declaration of Helsinki, and approved by the participating school boards and Kentalis/ Auris research board. Research was compliant with Radboud University and Kentalis/Auris ethics regulations at the time of data collection.

Informed Consent Statement: Informed consent was obtained from all subjects involved in the study.

Data Availability Statement: Data is stored at Radboud University's data repository and available upon request to the first author.

Acknowledgments: This research was supported by Viataal, the Koninklijke Effatha Guyot Groep, and the Mgr. J.C. van Overbeek Stichting.

Conflicts of Interest: The authors declare no conflict of interest. 


\section{Appendix A}

Fingerspelling test

The answer options in the test always contained the following options:

$\mathrm{V}$ incorrect vowel

C incorrect consonant

D entirely different

CA correct answer

Schae. (Schaerlakens) and Staph. (Staphorsius) refer to word frequency values.

\begin{tabular}{|c|c|c|c|c|c|c|c|c|c|c|c|}
\hline \multicolumn{2}{|l|}{ Items } & \multirow{2}{*}{$\begin{array}{l}\text { Schae. } \\
92\end{array}$} & \multirow{2}{*}{$\begin{array}{l}\text { Staph. } \\
586\end{array}$} & \multicolumn{8}{|c|}{ Answer options } \\
\hline 20. & nu & & & V & na & CA & nu & C & $\mathrm{mu}$ & $\mathrm{D}$ & al \\
\hline 1. & zee & 96 & 91 & $\mathrm{C}$ & mee & $\mathrm{V}$ & ze & CA & zee & $\mathrm{D}$ & wie \\
\hline 2. & bal & 93 & 30 & $\mathrm{C}$ & dal & CA & bal & $\mathrm{V}$ & bel & $\mathrm{D}$ & rat \\
\hline 3. & een & 97 & 5607 & $\mathrm{D}$ & tas & CA & een & $\mathrm{V}$ & aan & $\mathrm{C}$ & nee \\
\hline 7. & dag & 98 & 207 & $\mathrm{~V}$ & deeg & $\mathrm{D}$ & voet & $\mathrm{C}$ & dak & CA & dag \\
\hline 11. & pen & 99 & 11 & C & gen & D & lat & V & peen & CA & pen \\
\hline 15. & $\operatorname{man}$ & 98 & 124 & CA & man & $\mathrm{V}$ & maan & $\mathrm{D}$ & kies & C & nam \\
\hline 9. & dun & 95 & 15 & $\mathrm{~V}$ & deen & D & kas & V & gun & CA & dun \\
\hline 2. & mis & 97 & 11 & $\mathrm{~V}$ & mie & $\mathrm{C}$ & nis & CA & mis & $\mathrm{D}$ & erg \\
\hline 9. & teen & 99 & 1 & D & roos & $\mathrm{C}$ & neet & $\mathrm{V}$ & ton & CA & teen \\
\hline 18. & weer & 92 & 477 & $\mathrm{D}$ & hand & $\mathrm{V}$ & waar & C & veer & CA & weer \\
\hline 19. & deur & 90 & 48 & $\mathrm{C}$ & deun & D & iets & V & dier & CA & deur \\
\hline 17. & gauw & 99 & 72 & V & gouw & C & pauw & CA & gauw & $\mathrm{D}$ & blad \\
\hline 3. & niet & 92 & 1974 & V & noot & $\mathrm{D}$ & prop & C & tien & CA & niet \\
\hline 1. & mooi & 98 & 89 & $\mathrm{D}$ & vork & CA & mooi & $\mathrm{V}$ & maai & $\mathrm{C}$ & hooi \\
\hline 12. & zuur & 98 & 3 & CA & zuur & V & zeer & D & dier & C & guur \\
\hline 15. & zusje & 87 & 21 & $\mathrm{C}$ & lusje & $\mathrm{V}$ & zesje & $\mathrm{CA}$ & zusje & $\mathrm{D}$ & groet \\
\hline 23. & stuur & 93 & 93 & $\mathrm{D}$ & droom & CA & stuur & $\mathrm{C}$ & schuur & $\mathrm{V}$ & staar \\
\hline 1. & stout & 98 & 4 & CA & stout & V & staat & $\mathrm{D}$ & friet & C & fout \\
\hline 9. & pauze & 93 & 7 & $\mathrm{~V}$ & poze & $\mathrm{D}$ & stoep & CA & pauze & $\mathrm{C}$ & gauw \\
\hline 4. & nuttig & 18 & 5 & CA & nuttig & V & nattig & C & nukkig & $\mathrm{D}$ & papier \\
\hline 37. & muziek & 95 & 36 & $\mathrm{~V}$ & mozaïek & CA & muziek & D & radijs & C & publiek \\
\hline 11. & zouden & 81 & & $\mathrm{C}$ & houden & $\mathrm{D}$ & roepen & CA & zouden & $\mathrm{V}$ & zeiden \\
\hline 15. & kiezen & 91 & 19 & $\mathrm{D}$ & buiten & $\mathrm{V}$ & kazen & $\mathrm{C}$ & kieren & CA & kiezen \\
\hline 28. & bushalte & 91 & 2 & $\mathrm{C}$ & rusthalte & $\mathrm{D}$ & voetbalt & CA & bushalte & $\mathrm{V}$ & busholte \\
\hline 30. & luchtbed & 71 & 2 & V & lichtbed & CA & luchtbed & $\mathrm{C}$ & luchtbel & $\mathrm{D}$ & computer \\
\hline
\end{tabular}

\begin{tabular}{|c|c|c|c|c|c|c|c|c|c|}
\hline \multirow{3}{*}{$\begin{array}{l}\text { Items } \\
20 . \\
1 .\end{array}$} & \multicolumn{9}{|c|}{ English translations } \\
\hline & [now] & V & [after] & CA & [now] & $\mathrm{C}$ & {$[\mathrm{mu}]$} & D & [already] \\
\hline & [sea] & $\mathrm{C}$ & [along] & $\mathrm{V}$ & [she] & CA & [sea] & $\mathrm{D}$ & [who] \\
\hline 2. & [ball] & $\mathrm{C}$ & [valley] & CA & [ball] & $\mathrm{V}$ & [bell] & $\mathrm{D}$ & [rat] \\
\hline 3. & [one] & $\mathrm{D}$ & [bag] & CA & [one] & $\mathrm{V}$ & [on] & $\mathrm{C}$ & [no] \\
\hline 7. & [day] & $\mathrm{V}$ & [dough] & $\mathrm{D}$ & [foot] & $\mathrm{C}$ & [roof] & CA & [day] \\
\hline 11. & [pen] & $\mathrm{C}$ & [gene] & $\mathrm{D}$ & [slat] & $\mathrm{V}$ & [carrot] & CA & [pen] \\
\hline 15. & [man] & CA & [man] & $\mathrm{V}$ & [moon] & $\mathrm{D}$ & [molar] & $\mathrm{C}$ & [took] \\
\hline 9. & [skinny] & $\mathrm{V}$ & [dane] & $\mathrm{D}$ & [greenhouse] & $\mathrm{V}$ & [award] & CA & [skinny] \\
\hline 2. & [wrong] & $\mathrm{V}$ & [noodle] & $\mathrm{C}$ & [niche] & CA & [wrong] & $\mathrm{D}$ & [bad] \\
\hline 9. & [toe] & $\mathrm{D}$ & [rose] & $\mathrm{C}$ & [nit] & $\mathrm{V}$ & [barrel] & CA & [toe] \\
\hline 18. & [weather] & $\mathrm{D}$ & [hand] & $\mathrm{V}$ & [true] & C & [feather] & CA & [weather] \\
\hline 19. & [door] & C & [tune] & $\mathrm{D}$ & [anything] & $\mathrm{V}$ & [animal] & CA & [door] \\
\hline 17. & [soon] & $\mathrm{V}$ & [shire] & $\mathrm{C}$ & [peacock] & CA & [soon] & $\mathrm{D}$ & [leaf] \\
\hline 3. & [not] & $\mathrm{V}$ & [nut] & $\mathrm{D}$ & [plug] & $\mathrm{C}$ & [ten] & CA & [not] \\
\hline 1. & [beautiful] & $\mathrm{D}$ & [fork] & CA & [beautiful] & $\mathrm{V}$ & [mow] & $\mathrm{C}$ & [hay] \\
\hline 12. & [sour] & CA & [sour] & $\mathrm{V}$ & [pain] & $\mathrm{D}$ & [animal] & $\mathrm{C}$ & [lurid] \\
\hline 15. & [sister] & C & [knot] & $\mathrm{V}$ & [six] & CA & [sister] & $\mathrm{D}$ & [greeting] \\
\hline 23. & [wheel] & $\mathrm{D}$ & [dream] & CA & [wheel] & $\mathrm{C}$ & [shed] & $\mathrm{V}$ & [stare] \\
\hline 1. & [naughty] & CA & [naughty] & $\mathrm{V}$ & [state] & $\mathrm{D}$ & [fries] & C & [mistake] \\
\hline 9. & [break] & $\mathrm{V}$ & [posture] & $\mathrm{D}$ & [sidewalk] & CA & [break] & $\mathrm{C}$ & [soon] \\
\hline 4. & [useful] & CA & [useful] & $\mathrm{V}$ & [wet] & $\mathrm{C}$ & [fitful] & $\mathrm{D}$ & [paper] \\
\hline 37. & [music] & $\mathrm{V}$ & [mosaic] & CA & [music] & $\mathrm{D}$ & [radish] & $\mathrm{C}$ & [audience] \\
\hline 11. & [would] & $\mathrm{C}$ & [hold] & $\mathrm{D}$ & [call] & CA & [would] & $\mathrm{V}$ & [said] \\
\hline 15. & [choosing] & $\mathrm{D}$ & [outside] & $\mathrm{V}$ & [cheeses] & C & [cracks] & CA & [choosing] \\
\hline 28. & [bus stop] & $\mathrm{C}$ & [rest stop] & $\mathrm{D}$ & [football] & CA & [bus stop] & $\mathrm{V}$ & [bus cave] \\
\hline 30. & [air bed] & $\mathrm{V}$ & [light bed] & CA & [air bed] & C & [bubble] & $\mathrm{D}$ & [computer] \\
\hline
\end{tabular}


Speech phonological awareness

\begin{tabular}{|c|c|c|c|c|}
\hline Item & Target picture (1) & Picture 2 & Picture 3 & Picture 4 \\
\hline 1 & haan [rooster] & maan [moon] at position 3 & boek [book] & geit [goat] \\
\hline 2 & klok [clock] & sok [sock] at position 1 & post [post] & poes [cat] \\
\hline 3 & tas [bag] & jas [coat] at position 3 & jurk [dress] & zeep [soap] \\
\hline 4 & bad [bath] & gat [hole] at position 2 & zit [sit] & kar [wheelbarrow] \\
\hline 5 & kring [circle] & ring [ring] at position 1 & wolk [cloud] & ruit [window] \\
\hline 6 & boek [book] & broek [trousers] at position 2 & jurk [dress] & kaal [bold] \\
\hline 7 & paard [horse] & taart [pie] at position 3 & zit [sit] & straf [punishment] \\
\hline 8 & mug [mosquito] & rug [back] at position 1 & hoog [high] & kus [kiss] \\
\hline 9 & mes [knife] & fles [bottle] at position 3 & jas [jacket] & bal [ball] \\
\hline 10 & kip [chicken] & wip [teeter] at position 3 & pet [cap] & kin [chin] \\
\hline 11 & koe $[$ cow] & moe [tired] at position 1 & poes [cat] & jeuk [itchy] \\
\hline 12 & huis [house] & muis [mouse] at position 3 & reis [trip] & druif [grape] \\
\hline 13 & roos [rose] & boos [angry] at position 2 & boom [tree] & zoet [sweet] \\
\hline 14 & duur [expensive] & vuur [fire] at position 1 & raam [window] & boer [famer] \\
\hline 15 & fout [mistake] & koud [cold] at position 1 & boot [boat] & leeg [empty] \\
\hline 16 & bos [forest] & mos [moss] at position 3 & vol [full] & baas [boss] \\
\hline 17 & $\operatorname{man}[\mathrm{man}]$ & pan [pot] at position 1 & raam [window] & lamp [lamp] \\
\hline 18 & taart [pie] & zwaard [sword] at position 2 & worst [sausage] & vaas [vase] \\
\hline 19 & baas [boss] & kaas [cheese] at position 3 & reis [trip] & muur [wall] \\
\hline 20 & nek [neck] & hek [fence] at position 1 & nacht [night] & post [post] \\
\hline 21 & bus [bus] & zus [sister] at position 1 & bank [bench & raak [hit] \\
\hline 22 & boot [boat] & brood [bread] at position 1 & kam [comb] & fout [mistake] \\
\hline 23 & vis [fish] & mis [incorrect] at position 3 & zit [sit] & bril [glasses] \\
\hline 24 & blad [leaf] & gat [hole] at position 3 & berg [mountain] & das [tie] \\
\hline 25 & sterk [strong] & kerk [church] at position 2 & been [leg] & $\operatorname{dik}[\mathrm{fat}]$ \\
\hline 26 & kin [chin] & spin [spider] at position 3 & kip [chicken] & zuur [sour] \\
\hline 27 & soep [soup] & stoep [pavement] at position 1 & post [post] & buik [belly] \\
\hline 28 & krant [newspaper] & hand [hand] at position 3 & verf [paint] & melk [milk] \\
\hline 29 & zon $[\mathrm{sun}]$ & ton [barrel] at position 3 & kam [comb] & boer [farmer] \\
\hline 30 & $\operatorname{dik}$ [fat] & blik [tin] at position 1 & traan [tear] & lip [lip] \\
\hline 31 & pijn [pain] & trein [train] at position 2 & riem [belt] & lijm [glue] \\
\hline 32 & tang [pliers] & wang [cheek] at position 2 & gans [goose] & kan [jar] \\
\hline 33 & brand [fire] & krant [newspaper] at position 3 & helft [half] & woord [word] \\
\hline 34 & kraan [faucet] & zwaan [swan] at position 1 & koorts [fever] & raam [window] \\
\hline 35 & gras [grass] & das [tie] at position 1 & baas [boss] & tong [tongue] \\
\hline 36 & wijn [wine] & trein [train] at position 2 & duif [pidgeon & klok [clock] \\
\hline 37 & worst [sausage] & dorst [thursty] at position 1 & storm [storm & huis [house] \\
\hline 38 & neus [nose] & reus [giant] at position 2 & tuin [garden & kok [chef] \\
\hline 39 & zout [salt] & koud [cold] at position 3 & gang [hall] & post [post] \\
\hline 40 & blad [leaf] & gat [hole] at position 1 & pan [pot] & kin [chin] \\
\hline
\end{tabular}

Pictures used in this test are part of an educational tool 'Leesladder' [Reading ladder; Irausquin and Mommers 2001].

\section{Appendix B}

Independent samples $t$-tests revealed that at T2, the hearing children showed faster RTs and higher accuracy than the deaf children in the word reading fluency task (both $p$ s $<0.011)$. At T3, the hearing children showed higher accuracy $(p<0.001)$, but not faster RTs $(p=0.916)$, than the deaf children in the word reading task. The hearing participants also had significantly higher text reading fluency scores in the text reading task at both T2 and T3 (both $p s<0.001$ ). Figure A1 shows the average values and $t$-test results for each of the study measures. Similar results were observed for the year 3 and year 5 groups independently (see Table A1 for details). 
T2
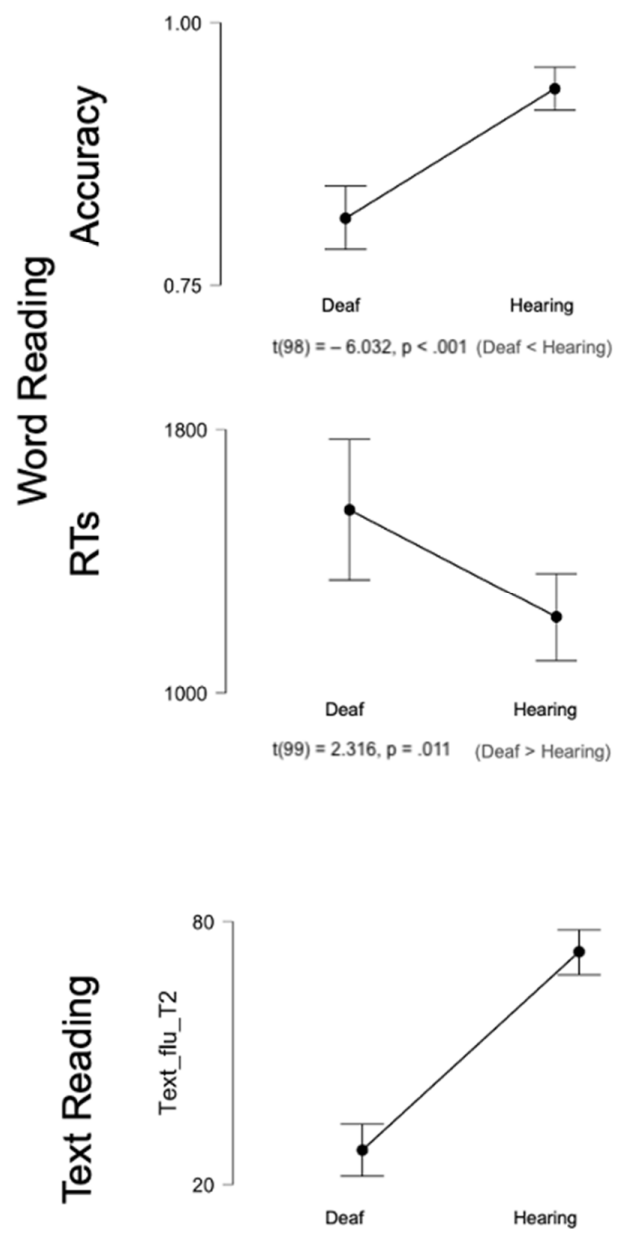

$t(100)=-10.679, p<.001 \quad$ (Deaf $<$ Hearing)
T3

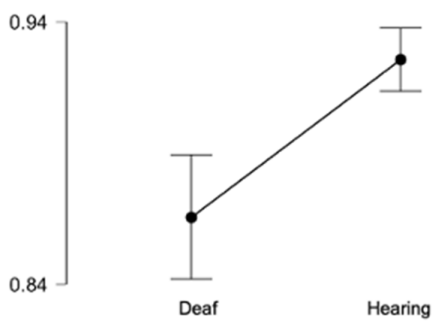

$t(98)=-3.804, p<.001$ (Deaf $<$ Hearing)

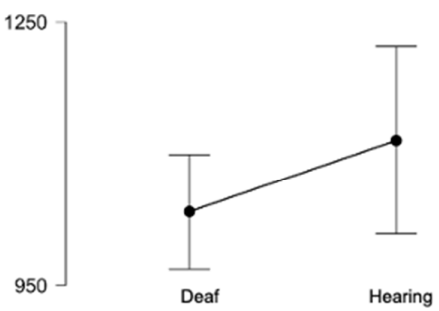

$\mathrm{t}(99)=-1.390, \mathrm{p}=.916$ (Deaf $>$ Hearing)
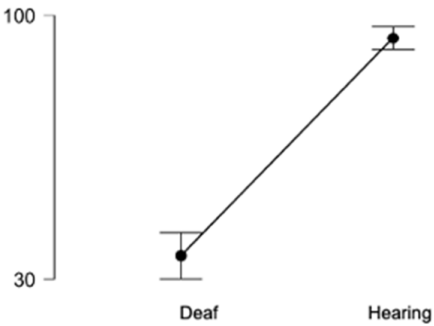

$\mathrm{t}(100)=-14.397, \mathrm{p}<.001 \quad$ (Deaf $<$ Hearing)

Figure A1. Average word reading accuracy and response times, and average text fluency accuracy at T2 and T3. Error bars represent the confidence intervals (95\%). The figure also shows the results from the independent sample $t$-tests for deaf and hearing participants in all the study measures.

Table A1. Behavioural data. Independent samples $t$-tests between deaf and hearing groups and separated by age group. Significant differences are bolded.

\begin{tabular}{|c|c|c|c|c|c|c|c|c|c|c|c|c|c|c|c|c|c|}
\hline & & \multicolumn{8}{|c|}{$\mathrm{T} 2$} & \multicolumn{8}{|c|}{ T3 } \\
\hline & & \multicolumn{2}{|c|}{ Deaf } & \multicolumn{2}{|c|}{ Hearing } & \multicolumn{4}{|c|}{ One Sample $t$-Test } & \multicolumn{2}{|c|}{ Deaf } & \multicolumn{2}{|c|}{ Hearing } & \multicolumn{4}{|c|}{ One Sample $t$-Test } \\
\hline & & Mean & SD & Mean & SD & Difference & $\mathbf{t}$ & df & $p$ & Mean & SD & Mean & SD & Difference & $\mathbf{t}$ & Df & $p$ \\
\hline \multirow{3}{*}{ All } & Word reading accuracy & 82 & 12 & 94 & 6 & -12 & -6.032 & 98 & $<.001$ & 87 & 9 & 93 & 4 & -6 & -3.804 & 99 & $<.001$ \\
\hline & Word reading RTs & 1557 & 823 & 1231 & 415 & 326 & 2.316 & 98 & .011 & 1034 & 258 & 1115 & 329 & -82 & -1.39 & 99 & .916 \\
\hline & Text reading & 28 & 23 & 73 & 16 & -45 & -1.679 & 100 & $<.001$ & 36 & 24 & 94 & 10 & -58 & -14.397 & 100 & $<.001$ \\
\hline \multirow{3}{*}{ Yr. 3} & Word reading accuracy & 75 & 12 & 92 & 9 & -17 & -5.477 & 48 & $<.001$ & 82 & 9 & 92 & 4 & -9 & -4.248 & 48 & $<.001$ \\
\hline & Word reading RTs & 1696 & 754 & 1499 & 414 & 197 & 1.065 & 48 & .146 & 1108 & 298 & 1304 & 300 & -196 & -2.274 & 48 & .986 \\
\hline & Text reading & 17 & 18 & 66 & 18 & -49 & -9.402 & 48 & $<.001$ & 25 & 18 & 91 & 13 & -66 & -14.321 & 48 & $<.001$ \\
\hline \multirow{3}{*}{ Yr. 5} & Word reading accuracy & 88 & 8 & 95 & 2 & -8 & -4.145 & 48 & $<.001$ & 91 & 7 & 94 & 3 & -3 & -1.623 & 49 & .056 \\
\hline & Word reading RTs & 1419 & 878 & 963 & 176 & 456 & 2.282 & 48 & .013 & 965 & 193 & 917 & 230 & 48 & 0.791 & 49 & .216 \\
\hline & Text reading & 38 & 23 & 80 & 12 & -42 & -7.443 & 50 & $<.001$ & 47 & 24 & 97 & 3 & -50 & -9.113 & 50 & $<.001$ \\
\hline
\end{tabular}




\section{Appendix C}

Table A2. Model summary for word accuracy at T2.

\begin{tabular}{|c|c|c|c|c|c|c|c|c|c|}
\hline \multirow[b]{2}{*}{ Model } & \multirow[b]{2}{*}{$\mathbf{R}$} & \multirow[b]{2}{*}{$\mathbf{R}^{2}$} & \multirow[b]{2}{*}{$\mathbf{R}^{2}$ adj } & \multirow[b]{2}{*}{ Std. Error } & \multicolumn{5}{|c|}{ Change Statistics } \\
\hline & & & & & $\mathrm{R}^{2}$ Change & F Change & df1 & df2 & Sig. F Change \\
\hline 1 & $0.492 \mathrm{a}$ & 0.242 & 0.229 & 0.103 & 0.242 & 18.508 & 1 & 58 & $<.001$ \\
\hline 2 & $0.647 \mathrm{~b}$ & 0.418 & 0.398 & 0.091 & 0.176 & 17.297 & 1 & 57 & $<.001$ \\
\hline 3 & $0.737 \mathrm{c}$ & 0.543 & 0.518 & 0.082 & 0.125 & 15.254 & 1 & 56 & $<.001$ \\
\hline 4 & $0.763 \mathrm{~d}$ & 0.582 & 0.552 & 0.079 & 0.039 & 5.159 & 1 & 55 & .027 \\
\hline
\end{tabular}

a Predictors: (Constant), Age; b Predictors: (Constant), Age, VocSP; c Predictors: (Constant), Age, VocSP, FSP; d Predictors: (Constant), Age, VocSP, FSP, PhoSP.

Table A3. Model summary for word RTs at T2.

\begin{tabular}{|c|c|c|c|c|c|c|c|c|c|}
\hline \multirow[b]{2}{*}{ Model } & \multirow[b]{2}{*}{$\mathbf{R}$} & \multirow[b]{2}{*}{$\mathbf{R}^{2}$} & \multirow[b]{2}{*}{$R^{2}$ adj } & \multirow[b]{2}{*}{ Std. Error } & \multicolumn{5}{|c|}{ Change Statistics } \\
\hline & & & & & $\mathrm{R}^{2}$ Change & F Change & df1 & df2 & Sig. F Change \\
\hline 1 & $0.348 \mathrm{a}$ & 0.121 & 0.106 & 778.545 & 0.121 & 7.973 & 1 & 58 & .006 \\
\hline 2 & $0.432 \mathrm{~b}$ & 0.186 & 0.158 & 755.591 & 0.065 & 4.577 & 1 & 57 & .037 \\
\hline
\end{tabular}

a Predictors: (Constant), FSP; b Predictors: (Constant), FSP, STM.

Table A4. Model summary for word accuracy at T3.

\begin{tabular}{cccccccccc}
\hline & \multicolumn{1}{c}{ Change Statistics } \\
\hline Model & $\mathbf{R}$ & $\mathbf{R}^{\mathbf{2}}$ & $\mathbf{R}^{\mathbf{2}}$ adj & Std. Error & $\mathbf{R}^{\mathbf{2}}$ Change & $\boldsymbol{F}$ Change & df1 & df2 & Sig. F Change \\
\hline 1 & $0.471 \mathrm{a}$ & 0.222 & 0.209 & 0.085 & 0.222 & 16.580 & 1 & 58 & $<.001$ \\
2 & $0.840 \mathrm{~b}$ & 0.71 & 0.696 & 0.0525 & 0.484 & 93.88 & 1 & 57 & $<.001$ \\
3 & $0.872 \mathrm{c}$ & 0.760 & 0.747 & 0.048 & 0.053 & 12.460 & 1 & 56 & .001 \\
4 & $0.882 \mathrm{~d}$ & 0.778 & 0.762 & 0.046 & 0.019 & 4.660 & 1 & 55 & .035 \\
\hline
\end{tabular}

a Predictors: (Constant), Age; b Predictors: (Constant), Age, Word Accuracy T2; c Predictors: (Constant), Age, Word Accuracy T2, PhoSP; d Predictors: (Constant), Age, Word Accuracy T2, PhoSP, FSP.

Table A5. Model summary for word RTs T3.

\begin{tabular}{cccccccccc}
\hline & \multicolumn{1}{c}{} & \multicolumn{1}{c}{ Change Statistics } \\
\hline Model & $\mathbf{R}$ & $\mathbf{R}^{\mathbf{2}}$ & $\mathbf{R}^{\mathbf{2}}$ adj & Std. Error & $\mathbf{R}^{\mathbf{2}}$ Change & $\boldsymbol{F}$ Change & df1 & df2 & Sig. F Change \\
\hline 1 & $0.305 \mathrm{a}$ & 0.093 & 0.077 & 250.800 & 0.093 & 5.951 & 1 & 58 & .018 \\
2 & $0.402 \mathrm{~b}$ & 0.162 & 0.132 & 243.240 & 0.069 & 4.661 & 1 & 57 & .035 \\
\hline
\end{tabular}

a Predictors: (Constant), Age; b Predictors: (Constant), Age, PhoSL.

Table A6. Model summary for text fluency at T2.

\begin{tabular}{cccccccccc}
\hline & \multicolumn{1}{c}{} & \multicolumn{4}{c}{ Change Statistics } \\
\hline Model & $\mathbf{R}$ & $\mathbf{R}^{\mathbf{2}}$ & $\mathbf{R}^{\mathbf{2}}$ adj & Std. Error & $\mathbf{R}^{\mathbf{2}}$ Change & $\boldsymbol{F}$ Change & df1 & df2 & Sig. F Change \\
\hline 1 & $0.437 \mathrm{a}$ & 0.191 & 0.178 & 21.060 & 0.191 & 14.190 & 1 & 60 & $<.001$ \\
2 & $0.685 \mathrm{~b}$ & 0.470 & 0.452 & 17.197 & 0.278 & 30.981 & 1 & 59 & $<.001$ \\
3 & $0.749 \mathrm{c}$ & 0.561 & 0.539 & 15.774 & 0.092 & 12.129 & 1 & 58 & .001 \\
\hline
\end{tabular}

a Predictors: (Constant), Age; b Predictors: (Constant), Age, VocSP; c Predictors: (Constant), Age, VocSP, FSP.

Table A7. Model summary for text fluency at T3.

\begin{tabular}{cccccccccc}
\hline & \multicolumn{1}{c}{ Change Statistics } \\
\hline Model & $\mathbf{R}$ & $\mathbf{R}^{\mathbf{2}}$ & $\mathbf{R}^{\mathbf{2}}$ adj & Std. Error & $\mathbf{R}^{\mathbf{2}}$ Change & $\boldsymbol{F}$ Change & df1 & df2 & Sig. F Change \\
\hline 1 & $0.486 \mathrm{a}$ & 0.236 & 0.223 & 21.484 & 0.236 & 17.948 & 1 & 58 & $<.001$ \\
2 & $0.720 \mathrm{~b}$ & 0.518 & 0.501 & 17.220 & 0.281 & 33.276 & 1 & 57 & $<.001$ \\
3 & $0.808 \mathrm{c}$ & 0.653 & 0.634 & 14.745 & 0.135 & 21.749 & 1 & 56 & $<.001$ \\
4 & $0.827 \mathrm{~d}$ & 0.684 & 0.661 & 14.184 & 0.032 & 5.509 & 1 & 55 & .023 \\
\hline
\end{tabular}

a Predictors: (Constant), Age; b Predictors: (Constant), Age, Word accuracy T2; c Predictors: (Constant), Age, Word accuracy T2, VocSP; d Predictors: (Constant), Age, Word accuracy T2, VocSP, FSP. 


\section{References}

Aarnoutse, Cor, and Jan van Leeuwe. 1998. Relation between reading comprehension, vocabulary, reading pleasure, and reading fluency. Educational Research and Evaluation 4: 143-66. [CrossRef]

Allen, Thomas E. 2015. ASL Skills, Fingerspelling ability, home communication context and early alphabetic knowledge of preschoolaged deaf children. Sign Language Studies 15: 233-65. [CrossRef]

Alloway, Tracy Packiam, Susan Elizabeth Gathercole, Anne-Marie Adams, Catherine Willis, Rachel Eaglen, and Emily Lamont. 2005. Working memory and phonological awareness as predictors of progress towards early learning goals at school entry. British Journal of Developmental Psychology 23: 417-26. [CrossRef]

Anthony, Jason L., Claire Davis, Jeffrey M. Williams, and Teresa I. Anthony. 2014. Preschoolers' oral language abilities: A multilevel examination of dimensionality. Learning and Individual Differences 35: 56-61. [CrossRef]

Antia, Shirin D., Amy R. Lederberg, Susan Easterbrooks, Brenda Schick, Lee Branum-Martin, Carol M. Connor, and Mi-Young Webb. 2020. Language and reading progress of young deaf and hard-of-hearing children. The Journal of Deaf Studies and Deaf Education 25: 334-50. [CrossRef]

Archbold, Sue, Margaret Harris, Gerard O’Donoghue, Thomas Nikolopoulos, Alison White, and Hazel Lloyd Richmond. 2008. Reading abilities after cochlear implantation: The effect of age at implantation on outcomes at 5 and 7 years after implantation. International Journal of Pediatric Otorhinolaryngology 72: 1471-78. [CrossRef]

Baayen, Harald, Richard Piepenbrock, and Hedderik van Rijn. 1993. The CELEX Lexical Database. Technical Report, Linguistic Data Consortium. Philadelphia: University of Pennsylvania.

Baker, Doris Luft, Deni Lee Basaraba, and Paul Polanco. 2016. Connecting the present to the past: Furthering the research on bilingual education and bilingualism. Review of Research in Education 40: 821-83. [CrossRef]

Bélanger, Nathalie N., and Keith Rayner. 2015. What Eye Movements Reveal about Deaf Readers. Current Directions in Psychological Science 24: 220-26. [CrossRef]

Bélanger, Nathalie N., Shari R. Baum, and Rachel I. Mayberry. 2012. Reading difficulties in adult deaf readers of French. Phonological codes, not guilty! Scientific Studies of Reading 16: 263-85. [CrossRef]

Bharadwaj, Sneha V., Denise Maricle, Laura Green, and Tamby Allman. 2015. Working memory, short-term memory and reading proficiency in school-age children with cochlear implants. International Journal of Pediatric Otorhinolaryngology 79: 1647-53. [CrossRef]

Bialystok, Ellen. 2018. Bilingual education for young children: Review of the effects and consequences. International Journal of Bilingual Education and Bilingualism 21: 666-79. [CrossRef] [PubMed]

Bornstein, Marc H., Chun-Shin Hahn, Diane L. Putnick, and Joan T. D. Suwalsky. 2014. Stability of core language skill from early childhood to adolescence: A latent variable approach. Child Development 85: 1346-56. [CrossRef] [PubMed]

Bouton, Sophie, Pascale Colé, Willy Serniclaes, Lynne G. Duncan, and Anne-Lise Giraud. 2015. Atypical phonological processing impairs written word recognition in children with cochlear implants. Language, Cognition and Neuroscience 30: 684-99. [CrossRef]

Buchanan-Worster, Elizabeth, Mairéad MacSweeney, Hannah Pimperton, Fiona Kyle, Margaret Harris, Indie Beedie, and Charles Hulme. 2020. Speechreading ability is related to phonological awareness and single-word reading in both deaf and hearing children. Journal of Speech, Language, and Hearing Research 63: 3775-85. [CrossRef]

Castles, Anne, and Max Coltheart. 2004. Is there a causal link from phonological awareness to success in learning to read? Cognition 91: 77-111. [CrossRef]

Castles, Anne, Kathleen Rastle, and Kate Nation. 2018. Ending the reading wars: Reading acquisition from novice to expert. Psychological Science in the Public Interest 19: 5-51. [CrossRef] [PubMed]

Cates, Deborah M., Matthew J. Traxler, and David P. Corina. 2021. Predictors of reading comprehension in deaf and hearing bilinguals. Applied Psycholinguistics 41: 1-43. [CrossRef]

Chamberlain, Charlene, and Rachel I. Mayberry. 2000. Theorizing about the relation between American Sign Language and reading. In Language Acquisition by Eye. Edited by Charlene Chamberlain, Jill P. Morford and Rachel I. Mayberry. Hillsdale: Lawrence Erlbaum Associates.

Connor, Carol M, and Teresa A. Zwolan. 2004. Examining multiple sources of influence on the reading comprehension skills of children who use cochlear implants. Journal of Speech, Language and Hearing Research 47: 509-26. [CrossRef]

Conrad, Reuben. 1970. Short-term memory processes in the deaf. British Journal of Psychology 61: 179-95. [CrossRef]

Corina, David P., Sarah Hafer, and Kearnan Welch. 2014. Phonological awareness for American Sign Language. Journal of Deaf Studies and Deaf Education 19: 530-45. [CrossRef]

Costello, Brendan, Sendy Caffarra, Noemi Fariña, Jon Andoni Duñabeitia, and Manuel Carreiras. 2021. Reading without phonology: ERP evidence from skilled deaf readers of Spanish. Scientific Reports 11: 5202. [CrossRef]

Crume, Peter K., Amy Lederberg, and Brenda Schick. 2021. Language and Reading Comprehension Abilities of Elementary SchoolAged Deaf Children. Journal of Deaf Studies and Deaf Education 26: 159-69. [CrossRef]

Daneman, Meredyth, S. Nemeth, Murray Stainton, and K. Huelsmann. 1995. Working memory as a predictor of reading achievement in orally educated hearing-impaired children. The Volta Review 97: 225-41.

de Klerk, Annet, de Connie Fortgens, and Annelies van der Eijk. 2015. Curriculum design in Dutch deaf education. In Educating Deaf Learners: Creating a Global Evidence Base. Edited by Harry Knoors and Marc Marschark. New York: Oxford University Press, pp. 573-93. 
DeLana, Melissa, Anne Mary Gentry, and Jean Andrews. 2007. The efficacy of ASL/English bilingual education: Considering public schools. American Annals of the Deaf 152: 73-87. [CrossRef] [PubMed]

De Raeve, Leo. 2010. A longitudinal study on auditory perception and speech intelligibility in deaf children implanted younger than 18 months in comparison to those implanted at later ages. Otology \& Neurotology 31: 1261-67.

Dickinson, David K., Allyssa McGabe, Louisa Anastapoulos, Ellen S. Peisner-Feinberg, and Michele D. Poe. 2003. The comprehensive language approach to early literacy: The interrelationships among vocabulary, phonological sensitivity, and print knowledge among preschool-aged children. Journal of Educational Psychology 95: 465-81. [CrossRef]

Di Luca, Samuel, and Mauro Pesenti. 2011. Finger numeral representations: More than just another symbolic code. Frontiers in Psychology 2: 272. [CrossRef] [PubMed]

Dillon, Caitlin M., Kenneth de Jong, and David B. Pisoni. 2012. Phonological awareness, reading skills, and vocabulary knowledge in children who use cochlear implants. Journal of Deaf studies and Deaf Education 17: 205-26. [CrossRef] [PubMed]

Durand, Marianne, Charles Hulme, Rebecca Larkin, and Margaret Snowling. 2005. The cognitive foundations of reading and arithmetic skills in 7- to 10-year olds. Journal of Experimental Child Psychology 91: 113-36. [CrossRef]

Dyer, Annabella, Mairéad MacSweeney, Marçin Szczerbinski, Louise Green, and Ruth Campbell. 2003. Predictors of reading delay in deaf adolescents: The relative contributions of rapid automatised naming speed and phonological awareness and decoding. Journal of Deaf Studies and Deaf Education 8: 215-29. [CrossRef]

Easterbrooks, Susan R., and Sandra G. Huston. 2008. The signed reading fluency of students who are deaf/hard of hearing. Journal of Deaf Studies and Deaf Education 13: 37-54. [CrossRef] [PubMed]

Edwards, Lindsey, Lynne Aitkenhead, and Dawn Langdon. 2016. The contribution of short-term memory capacity to reading ability in adolescents with cochlear implants. International Journal of Pediatric Otorhinolaryngology 90: 37-42. [CrossRef]

Emmorey, Karen. 2020. The neurobiology of reading differs for deaf and hearing adults. In The Oxford Handbook of Deaf Studies in Learning and Cognition. Oxford: Oxford University Press, p. 347.

Emmorey, Karen, and Brittany Lee. 2021. The neurocognitive basis of skilled reading in prelingually and profoundly deaf adults. Language and Linguistics Compass 15: e12407. [CrossRef] [PubMed]

Emmorey, Karen, Katherine J. Midgley, Casey B. Kohen, Zed Sevcikova Sehyr, and Phil J. Holcomb. 2017. The N170 ERP component differs in laterality, distribution, and association with continuous reading measures for deaf and hearing readers. Neuropsychologia 106: 298-309. [CrossRef] [PubMed]

Emmorey, Karen, Phil J. Holcomb, and Katherine J. Midgley. 2021. Masked ERP repetition priming in deaf and hearing readers. Brain and Language 214: 104903. [CrossRef]

Fariña, Noemi, Jan Andoni Duñabeitia, and Manuel Carreiras. 2017. Phonological and orthographic coding in deaf skilled readers. Cognition 168: 27-33. [CrossRef]

Fischer, Martin H. 2012. A hierarchical view of grounded, embodied, and situated numerical cognition. Cognitive Processing 13: 161-64. [CrossRef]

García, Ricardo J., and Kate Cain. 2014. Decoding and reading comprehension: A meta-analysis to identify which reader and assessment characteristics influence the strength of the relationship in English. Review of Educational Research 84: 75-111. [CrossRef]

Geers, Ann, and Jean Moog. 1989. Factors predictive of the development of literacy in profoundly hearing-impaired adolescents. The Volta Review 91: 69-86.

Giezen, Marcel R., Anne E. Baker, and Paola Escudero. 2014. Relationships between spoken word and sign processing in children with cochlear implants. Journal of Deaf Studies and Deaf Education 19: 107-25. [CrossRef]

Gough, Philip B., and William E. Tunmer. 1986. Decoding, reading, and reading disability. Remedial and Special Education 7: 6-10. [CrossRef]

Gutierrez-Sigut, Eva, Marta Vergara-Martínez, Ana Marcet, and Manuel Perea. 2018. Automatic use of phonological codes during word recognition in deaf signers of Spanish Sign Language. FEAST Formal and Experimental Advances in Sign Language Theory 1: 1-15.

Gutierrez-Sigut, Eva, Marta Vergara-Martinez, and Manuel Perea. 2017. Early use of phonological codes in deaf readers: An ERP study. Neuropsychologia 106: 261-79. [CrossRef] [PubMed]

Gutierrez-Sigut, Eva, Marta Vergara-Martinez, and Manuel Perea. 2019. Deaf readers benefit from lexical feedback during orthographic processing. Scientific Reports 9: 12321. [CrossRef] [PubMed]

Gutierrez-Sigut, Eva, Marta Vergara-Martinez, and Manuel Perea. 2022. The impact of visual cues during visual word recognition in deaf readers: An ERP study. Cognition 218: 104938. [CrossRef] [PubMed]

Hanson, Vicki L., and Carol A. Fowler. 1987. Phonological coding in word reading: Evidence from hearing and deaf readers. Memory $\mathcal{E}$ Cognition 15: 199-207.

Haptonstall-Nykaza, Tamara S., and Brenda Schick. 2007. The transition from fingerspelling to English print: Facilitating English decoding. Journal of Deaf Studies and Deaf Education 12: 172-83. [CrossRef]

Harris, Margaret, and Constanza Moreno. 2004. Deaf children's use of phonological coding: Evidence from reading, spelling and working memory. Journal of Deaf Studies and Deaf Education 3: 205-16. [CrossRef]

Harris, Margaret, and John R. Beech. 1998. Implicit phonological awareness and early reading development in prelingually deaf children. Journal of Deaf Studies and Deaf Education 3: 205-16. [CrossRef]

Harris, Margaret, Emmanouela Terlektsi, and Fiona Kyle. 2017. Concurrent and longitudinal predictors of reading for deaf and hearing children in primary school. Journal of Deaf Studies and Deaf Education 22: 233-42. [CrossRef] 
Herman, Rosalind, Fiona E. Kyle, and Penny Roy. 2019. Literacy and phonological skills in oral deaf children and hearing children with a history of dyslexia. Reading Research Quarterly 54: 553-75. [CrossRef]

Hermans, Daan, Ellen Ormel, and Harry Knoors. 2010. On the relation between the signing and reading skills of deaf bilinguals. International Journal of Bilingual Education and Bilingualism 13: 187-99. [CrossRef]

Hermans, Daan, Harry Knoors, and Ludo Verhoeven. 2007. Testbatterij voor de Nederlandse Gebarentaal [Assessment tool for Sign Language of the Netherlands]. Sint-Michielsgestel: Kentalis.

Hermans, Daan, Harry Knoors, Ellen Ormel, and Ludo Verhoeven. 2008a. Modeling reading vocabulary learning in deaf children in bilingual education programs. Journal of Deaf Studies and Deaf Education 13: 155-74. [CrossRef] [PubMed]

Hermans, Daan, Harry Knoors, Ellen Ormel, and Ludo Verhoeven. 2008b. The relationship between the reading and signing skills of deaf children in bilingual education programs. Journal of Deaf Studies and Deaf Education 13: 518-30. [CrossRef]

Hermans, Daan, Lian van Berkel-van Hoof, and Harry Knoors. 2021. Vocabulary learning in children with cochlear implants in signed and spoken modalities. In The Oxford Handbook of Deaf Studies in Literacy. Edited by Susan R. Easterbrooks and Hannah S. Dostal. New York: Oxford University Press, pp. 111-26.

Hirshorn, Elizabeth A., Matthew W. G. Dye, Peter Hauser, Ted R. Supalla, and Daphne Bavelier. 2015. The contribution of phonological knowledge, memory, and language background to reading comprehension in deaf populations. Frontiers in Psychology 6: 1153. [CrossRef]

Hoffmeister, Robert. 2000. A piece of the puzzle: ASL and reading comprehension in deaf children. In Language Acquisition by Eye. Edited by Charlene Chamberlain, Jill P. Morford and Rachel I. Mayberry. Hillsdale: Lawrence Erlbaum Associates, pp. 143-63.

Holmer, Emil, Mikael Heimann, and Mary Rudner. 2016. Evidence of an association between sign language phonological awareness and word reading in deaf and hard-of-hearing children. Research in Developmental Disabilities 48: 145-59. [CrossRef] [PubMed]

Holmer, Emil, Mikael Heimann, and Mary Rudner. 2017. Computerized sign language-based literacy training for deaf and hard-ofhearing children. The Journal of Deaf Studies and Deaf Education 22: 404-21. [CrossRef]

Humphries, Tom, and Francine MacDougall. 1999. "Chaining" and other links: Making connections between American Sign Language and English in Two Types of School Settings. Visual Anthropology Review 15: 84-94. [CrossRef]

Irausquin, R., and C. Mommers. 2001. Leesladder. Een Programma voor Kinderen met Leesmoeilijkheden. [Reading Ladder. A Program for Children with Reading Difficulties]. Tilburg: Zwijsen.

Izzo, Andrea. 2002. Phonemic awareness and reading ability: An investigation with young readers who are deaf. American Annals of the Deaf 147: 18-28. [CrossRef]

Karchmer, Michael A., and Ross E. Mitchell. 2003. Demographic and achievement characteristics of deaf and hard-of-hearing students. In The Oxford Handbook of Deaf Studies, Language and Education. Edited by Marc Marschark and Patricia Spencer. New York: Oxford University Press, pp. 21-37.

Katz, Leonard, and Ram Frost. 1992. The reading process is different for different orthographies: The orthographic depth hypothesis. In Advances in Psychology. Amsterdam: NorthHolland Publishing Company, vol. 94, pp. 67-84.

Keck, Tamara, and Keith Wolgemuth. 2020. American sign language phonological awareness and english reading abilities: Continuing to explore new relationships. Sign Language Studies 20: 334-54. [CrossRef]

Kelly, Leonard P. 2003. The importance of processing automaticity and temporary storage capacity to the differences in comprehension between skilled and less skilled college-age Deaf readers. Journal of Deaf Studies and Deaf Education 8: 230-49. [CrossRef]

Knoors, Harry, Maria Brons, and Marc Marschark. 2019. Deaf education beyond the western world: An introduction. In Deaf Education Beyond the Western World. Edited by Harry Knoors, Maria Brons and Marc Marschark. New York: Oxford University Press, pp. 1-18.

Krom, Rob S. H. 2001. Leestechniek E Leestempo. Arnhem: Citogroep.

Krakow, Rena Arens, and Vicki L. Hanson. 1985. Deaf signers and serial recall in the visual modality: Memory for signs, fingerspelling, and print. Memory \& Cognition 13: 265-72.

Kyle, Fiona E., and Margaret Harris. 2006. Concurrent correlates and predictors of reading and spelling achievement in deaf and hearing school children. Journal of Deaf Studies and Deaf Education 11: 273-88. [CrossRef] [PubMed]

Kyle, Fiona E., and Margaret Harris. 2010. Predictors of reading development in deaf children: A 3-year longitudinal study. Journal of Experimental Child Psychology 107: 229-43. [CrossRef] [PubMed]

Kyle, Fiona E., and Margaret Harris. 2011. Longitudinal patterns of emerging literacy in beginning deaf and hearing readers. Journal of Deaf Studies and Deaf Education 16: 289-304. [CrossRef] [PubMed]

Kyle, Fiona E., Ruth Campbell, and Mairéad MacSweeney. 2016. The relative contributions of speechreading and vocabulary to deaf and hearing children's reading ability. Research in Developmental Disabilities 48: 13-24. [CrossRef]

Langereis, M., and Anneke Vermeulen. 2011. Long Term outcomes of CI. Paper presented at the 10th European Symposium on Paediatric Cochlear Implantation, Athens, Greece, May 12-15.

Lederberg, Amy R., Lee Branum-Martin, Mi-Young Webb, Brenda Schick, Shirin Antia, Susan R. Easterbrooks, and Carol McDonald Connor. 2019. Modality and interrelations among language, reading, spoken phonological awareness, and fingerspelling. The Journal of Deaf Studies and Deaf Education 24: 408-23. [CrossRef] [PubMed]

Luetke-Stahlman, Barbara, and Diane Corcoran Nielsen. 2003. The contribution of phonological awareness and receptive and expressive English to the reading ability of deaf students with varying degrees of exposure to accurate English. Journal of Deaf Studies and Deaf Education 8: 464-84. [CrossRef] 
MacSweeney, Mairéad, Usha Goswami, and Helen Neville. 2013. The neurobiology of rhyme judgment by deaf and hearing adults: An ERP study. Journal of Cognitive Neuroscience 25: 1037-48. [CrossRef]

Marschark, Marc, and Thomas S. Mayer. 1998. Mental representation and memory in deaf adults and children. Psychological Perspectives on Deafness 2: 53-77.

Marschark, Marc, Cathy Rhoten, and Megan Fabich. 2007. Effects of cochlear implants on children's reading and academic achievement. The Journal of Deaf Studies and Deaf Education 12: 269-82. [CrossRef]

Marschark, Marc, Harry G. Lang, and John A. Albertini. 2002. Educating Deaf Students. From Research to Practice. New York: Oxford University Press.

Mayberry, Rachel. I., Alex A. del Giudice, and Amy M. Lieberman. 2011. Reading achievement in relation to phonological coding and awareness in deaf readers: A meta-analysis. Journal of Deaf Studies and Deaf Education 16: 164-88. [CrossRef] [PubMed]

Mayer, Connie, and Beverly J. Trezek. 2020. English literacy outcomes in sign bilingual programs: The current state of knowledge. American Annals of the Deaf 164: 560-76. [CrossRef] [PubMed]

Mayer, Connie, and Gordon Wells. 1996. Can the linguistic interdependence theory support a bilingual-bicultural model of literacy education for deaf students? Journal of Deaf Studies and Deaf Education 1: 93-107. [CrossRef] [PubMed]

Mayer, Connie L., Linda Watson, Sue Archbold, Zheng Yen Ng, and Imran Mulla. 2016. Reading and writing skills of deaf pupils with cochlear implants. Deafness $\mathcal{E}$ Education International 18: 71-86.

McQuarrie, Lynn, and Marilyn Abbott. 2013. Bilingual deaf students' phonological awareness in ASL and reading skills in English. Sign Language Studies 14: 80-100. [CrossRef]

McQuarrie, Lynn, and Rauno Parrila. 2009. Phonological representations in deaf children: Rethinking the "functional equivalence" hypothesis. Journal of Deaf Studies and Deaf Education 14: 137-54. [CrossRef]

McQuarrie, Lynn, and Rauno Parrila. 2014. Literacy and linguistic development in bilingual deaf children: Implications of the "and" for phonological processing. American Annals of the Deaf 159: 372-84. [CrossRef]

Merrills, Jill D., Geoffrey Underwood, and David J. Wood. 1994. The word recognition skills of profoundly, prelingually deaf children. British Journal of Developmental Psychology 12: 365-84. [CrossRef]

Miller, Paul. 1997. The effect of communication mode on the development of phonemic awareness in prelingually deaf students. Journal of Speech, Language, and Hearing Research 40: 1151-63. [CrossRef]

Miller, Paul. 2010. Phonological, orthographic, and syntactic awareness and their relation to reading comprehension in prelingually deaf individuals: What can we learn from skilled readers? Journal of Developmental and Physical Disabilities 22: 549-80. [CrossRef]

Miller, Paul, Efrat Banado-Aviran, and Orit E. Hetzroni. 2021. Developing reading skills in prelingually deaf preschool children: Fingerspelling as a strategy to promote orthographic learning. Journal of Deaf Studies and Deaf Education 26: 363-80. [CrossRef]

Miller, Paul, Tevhide Kargin, and Birkan Guldenoglu. 2015. Deaf native signers are better readers than nonnative signers: Myth or truth? Journal of Deaf Studies and Deaf Education 20: 147-62. [PubMed]

Moores, Donald F., and Catherine Sweet. 1990. Relationships of English grammar and communicative fluency to reading in deaf adolescents. Exceptionality: A Special Education Journal 1: 97-106. [CrossRef]

Moreno-Pérez, Francisco J., David Saldaña, and Isabel R. Rodríguez-Ortiz. 2015. Reading efficiency of deaf and hearing people in Spanish. Journal of Deaf Studies and Deaf Education 20: 374-84. [CrossRef] [PubMed]

Morford, Jill P., Corinne Occhino-Kehoe, Pilar Piñar, Erin Wilkinson, and Judy F. Kroll. 2017. The time course of cross language activation in deaf ASL English bilinguals. Bilingualism: Language and Cognition 20: 337-50. [CrossRef] [PubMed]

Morford, Jill P., Erin Wilkinson, Agnes Villwock, Pilar Pinar, and Judy F. Kroll. 2011. When deaf signers read English: Do written words activate their sign translations? Cognition 118: 286-92. [CrossRef] [PubMed]

Musselman, Carol. 2000. How do children who can't hear learn to read an alphabetic script: A review of the literature of reading and deafness. Journal of Deaf Studies and Deaf Education 5: 9-31. [CrossRef]

Ormel, Ellen, Daan Hermans, Harry Knoors, and Ludo Verhoeven. 2010. Phonological activation during visual word recognition in deaf and hearing children. Journal of Speech, Language, and Hearing Research 53: 1-19. [CrossRef]

Ormel, Ellen, Daan Hermans, Harry Knoors, and Ludo Verhoeven. 2012. Cross-language effects in visual word recognition: The case of bilingual deaf children. Bilingualism: Language and Cognition 15: 288-303. [CrossRef]

Padden, Carol. 2006. Learning to fingerspell twice: Young signing children's acquisition of fingerspelling. In Advances in the Sign Language Development of Deaf Children. Edited by Brenda Schhick, Marc Marschark and Patricia Elizabeth Spencer. Oxford: Oxford University Press, pp. 189-201.

Padden, Carol, and Claire Ramsey. 2000. American Sign Language and reading ability in deaf children. In Language Acquisition by Eye. Edited by Charlene Chamberlain, Jill P. Morford and Rachel I. Mayberry. Hillsdale: Lawrence Erlbaum Associates, pp. 165-89.

Perfetti, Charles A., and Rebecca Sandak. 2000. Reading optimally builds on spoken language: Implications for Deaf readers. Journal of Deaf Studies and Deaf Education 5: 32-50. [CrossRef]

Petitto, Laura-Ann, Clifton Langdon, Adam Stone, Diana Andriola, Geo Kartheiser, and Casey Cochran. 2016. Visual sign phonology: Insights into human reading and language from a natural soundless phonology. Wiley Interdisciplinary Reviews: Cognitive Science 7: 366-81. [CrossRef] [PubMed]

Pisoni, David, William Kronenberger, Adrienne Roman, and Ann Geers. 2011. Article 7: Measures of digit span and verbal rehearsal speed in deaf children following more than 10 years of cochlear implantation. Ear and Hearing 32: 60s-74s. [CrossRef] [PubMed] 
Pisoni, David B., Miranda Cleary, Ann E. Geers, and Emily A. Tobey. 1999. Individual differences in effectiveness of cochlear implants in children who are prelingually deaf: New process measures of performance. The Volta Review 101: 111-64. [PubMed]

Qi, Sen, and Ross E. Mitchell. 2012. Large-scale academic achievement testing of deaf and hard-of-hearing students: Past, present, and future. Journal of Deaf Studies and Deaf Education 17: 1-18. [CrossRef]

Schaerlaekens, Anne-Marie, Geldolph Adriaan Kohnstamm, and Maryline Lejaegere. 1999. Streeflijst Woordenschat voor Zesjarigen: Derde Herziene Versie Gebaseerd op Nieuw Onderzoek in Nederland en België [Target List Vocabulary for 6-Year-Old Children]. Lisse: Swets \& Zeitlinger.

Scott, Jessica A., and Robert J. Hoffmeister. 2016. American Sign Language and academic English: Factors influencing the reading of bilingual secondary school deaf and hard of hearing students. The Journal of Deaf Studies and Deaf Education 22: 59-71. [CrossRef]

Sehyr, Zed Sevcikova, Jennifer Petrich, and Karen Emmorey. 2016. Fingerspelled and Printed Words Are Recoded into a Speech-based Code in Short-term Memory. Journal of Deaf Studies and Deaf Education 22: 72-87. [CrossRef]

Schauwers, Karen, Steven Gillis, Kristin Daemers, Carina De Beukelaer, and Paul J. Govaerts. 2004. Cochlear implantation between 5 and 20 months of age: The onset of babbling and the audiologic outcome. Otology E Neurotology 25: 263-70.

Spencer, Linda J., and Jacob J. Oleson. 2008. Early listening and speaking skills predict later reading proficiency in pediatric cochlear implant users. Ear and Hearing 29: 270-80. [CrossRef]

Staphorsius, G. K., R. S. H. Krom, and K. de Geus. 1988. Frequenties van Woordvormen en Letterposities in Jeugdlectuur [Frequenties of Word Forms and Letter Positions in Books for the Youth]. Arnhem: Instituut voor Toetsontwikkeling (CITO).

Stone, Adam, Geo Kartheiser, Peter C. Hauser, Laura-Ann Petitto, and Thomas E. Allen. 2015. Fingerspelling as a novel gateway into reading fluency in deaf bilinguals. PLoS ONE 10: e0139610. [CrossRef]

Strong, Michael, and Philip M. Prinz. 2000. Is American Sign Language related to English Literacy? In Language Acquisition by Eye Edited by Charlene Chamberlain, Jill P. Morford and Rachel I. Mayberry. Hillsdale: Lawrence Erlbaum Associates, pp. 131-41.

Tang, Gladys, Scholastica Lam, and Kunman Chris Yiu. 2014. Language Development of Deaf Children in a Sign Bilingual and Co-enrollment Environment. In Bilingualism and Bilingual Deaf Education. Edition: Perspectives on Deafness. Edited by Marc Marschark, Gladys Tang and Harry Knoors. New York: Oxford University Press.

Transler, Catherine, and Pieter Reitsma. 2005. Phonological coding in reading of deaf children: Pseudohomophone effects in lexical decision. British Journal of Developmental Psychology 23: 525-42. [CrossRef]

Treiman, Rebecca, and Kathryn Hirsh-Pasek. 1983. Silent reading: Insights from second-generation Deaf readers. Cognitive Psychology 15: 39-65. [CrossRef]

van Berkel-van Hoof, Lian, Daan Hermans, Harry Knoors, and Ludo Verhoeven. 2016. Benefits of augmentative signs in word learning: Evidence from children who are deaf/hard of hearing and children with specific language impairment. Research in Developmental Disabilities 59: 338-50. [CrossRef]

Verhoeven, Ludo, and Anne Vermeer. 2001. Taaltoets Alle Kinderen [Language Test All Children]. Arnhem: CITO.

Verhoeven, Ludo, Pieter Reitsma, and Linda S. Siegel. 2011. Cognitive and linguistic factors in reading acquisition. Reading and Writing 24: 387-94. [CrossRef] [PubMed]

Vermeulen, Anneke M., Wim Van Bon, Rob Schreuder, Harry Knoors, and Ad Snik. 2007. Reading comprehension of deaf children with cochlear implants. Journal of Deaf Studies and Deaf Education 12: 283-302. [CrossRef] [PubMed]

Villwock, Agnes, Erein Wilkinson, Pilar Piñar, and Jill P. Morford. 2021. Language development in deaf bilinguals: Deaf middle school students co-activate written English and American Sign Language during lexical processing. Cognition 211: 104642. [PubMed]

Waters, Gloria S., and Donald G. Doehring. 1990. Reading acquisition in Congenitally Deaf Children Who Communicate Orally: Insights from an Analysis of Component Reading, Language, and Memory Skills. In Reading and its development. Edited by Thomas H. Carr and Betty Ann Levy. San Diego: Academic Press, pp. 323-73.

Wauters, Loes N., and Annet de Klerk. 2014. Improving reading instruction to deaf and hard-of-hearing students. In Bilingualism and Bilingual Deaf Education. Edited by Marc Marschark, Gladys Tang and Harry Knoors. New York: Oxford University Press, pp. 242-71.

Wauters, Loes N., Hille van Gelder, and Corrie Tijsseling. 2021. Simple View of Reading in Deaf and Hard-of-Hearing Adults. The Journal of Deaf Studies and Deaf Education 26: 535-45. [CrossRef]

Wauters, Loes N., Wim van Bon, and Agnes Tellings. 2006. Reading comprehension of Dutch deaf children. Reading and Writing 19: 49-76. [CrossRef]

Yiu, Chris Kun-man, Gladys Tang, and Chloe Chi-man Ho. 2019. Essential Ingredients for Sign Bilingualism and Co-Enrollment Education in the Hong Kong Context. In Co-Enrollment in Deaf Education. Edited by Marc Marschark, Shirin Antia and Harry Knoors. New York: Oxford University Press, pp. 83-106. 